\title{
Metabolomics and Dual RNA-Sequencing on Root Nodules Revealed New Cellular Functions Controlled by Paraburkholderia phymatum NifA
}

\author{
Paula Bellés-Sancho ${ }^{1}$ (D), Martina Lardi ${ }^{1}$, Yilei Liu ${ }^{1}$, Leo Eberl ${ }^{1}$, Nicola Zamboni ${ }^{2}$, Aurélien Bailly ${ }^{1, *(D)}$ and \\ Gabriella Pessi ${ }^{1, *(D)}$ \\ 1 Department of Plant and Microbial Biology, University of Zürich, CH-8057 Zürich, Switzerland; \\ paula.belles@botinst.uzh.ch (P.B.-S.); lardimartina@gmail.com (M.L.); yilei.liu@botinst.uzh.ch (Y.L.); \\ leberl@botinst.uzh.ch (L.E.) \\ 2 ETH Zürich, Institute of Molecular Systems Biology, CH-8093 Zürich, Switzerland; \\ zamboni@imsb.biol.ethz.ch \\ * Correspondence: aurelien.bailly@botinst.uzh.ch (A.B.); gabriella.pessi@botinst.uzh.ch (G.P.)
}

\section{check for} updates

Citation: Bellés-Sancho, P.; Lardi, M.; Liu, Y.; Eberl, L.; Zamboni, N.; Bailly, A.; Pessi, G. Metabolomics and Dual RNA-Sequencing on Root Nodules Revealed New Cellular Functions Controlled by Paraburkholderia phymatum NifA. Metabolites 2021, 11, 455. https://doi.org/10.3390/ metabo11070455

Academic Editors: Victoria Pastor and Pierre Pétriacq

Received: 4 June 2021

Accepted: 12 July 2021

Published: 15 July 2021

Publisher's Note: MDPI stays neutral with regard to jurisdictional claims in published maps and institutional affiliations.

Copyright: (c) 2021 by the authors. Licensee MDPI, Basel, Switzerland. This article is an open access article distributed under the terms and conditions of the Creative Commons Attribution (CC BY) license (https:/ / creativecommons.org/licenses/by/ $4.0 /)$.

\begin{abstract}
Paraburkholderia phymatum STM815 is a nitrogen-fixing endosymbiont that nodulate the agriculturally important Phaseolus vulgaris and several other host plants. We previously showed that the nodules induced by a STM815 mutant of the gene encoding the master regulator of nitrogen fixation NifA showed no nitrogenase activity $\left(\mathrm{Fix}^{-}\right)$and increased in number compared to $P$. vulgaris plants infected with the wild-type strain. To further investigate the role of NifA during symbiosis, nodules from P. phymatum wild-type and nifA mutants were collected and analyzed by metabolomics and dual RNA-Sequencing, allowing us to investigate both host and symbiont transcriptome. Using this approach, several metabolites' changes could be assigned to bacterial or plant responses. While the amount of the $\mathrm{C}_{4}$-dicarboxylic acid succinate and of several amino acids was lower in Fix ${ }^{-}$ nodules, the level of indole-acetamide (IAM) and brassinosteroids increased. Transcriptome analysis identified P. phymatum genes involved in transport of $\mathrm{C}_{4}$-dicarboxylic acids, carbon metabolism, auxin metabolism and stress response to be differentially expressed in absence of NifA. Furthermore, P. vulgaris genes involved in autoregulation of nodulation $(\mathrm{AON})$ are repressed in nodules in absence of NifA potentially explaining the hypernodulation phenotype of the nifA mutant. These results and additional validation experiments suggest that $P$. phymatum STM815 NifA is not only important to control expression of nitrogenase and related enzymes but is also involved in regulating its own auxin production and stress response. Finally, our data indicate that $P$. vulgaris does sanction the nif $A$ nodules by depleting the local carbon allocation rather than by mounting a strong systemic immune response to the $\mathrm{Fix}^{-}$rhizobia.
\end{abstract}

Keywords: symbiosis; nitrogenase; $\mathrm{C}_{4}$-dicarboxylates; auxin; brassinosteroid; flavonoid; stress response

\section{Introduction}

Nitrogen-fixing symbiosis between rhizobia and plants of the Fabaceae family significantly contributes more than half of the biosphere's available nitrogen to agriculture [1]. This process is known as biological nitrogen fixation (BNF) and takes place in specialized root and stem organs, called nodules, where rhizobia differentiate into bacteroids and convert atmospheric nitrogen into ammonium [2]. This enzymatic conversion, carried out by the oxygen-sensitive bacterial enzyme nitrogenase, requires large amounts of energy and reductants. The plant supplies bacteroids with carbon sources such as the $\mathrm{C}_{4}$-dicarboxylates succinate, malate and fumarate, which are imported by the $\mathrm{C}_{4}$-dicarboxylate transport (Dct) systems and are utilized as energy source [3,4]. Rhizobia are a taxonomically diverse group of bacteria, which belong to the alpha- and beta-subclass of proteobacteria $[5,6]$. Paraburkholderia phymatum STM815 is an aerobic soil bacterium, which was isolated in 
2001 and has since been shown to nodulate the roots of a broad range of mimosoid and papilionoid plants and develop a nitrogen-fixing symbiosis [7-12].

The establishment of an effective symbiosis between rhizobia and fabacean plants involves a complex molecular dialogue between the two partners, which is based on different plant and rhizobial molecules. In response to specific flavonoids secreted by the host species, rhizobia induce the expression of the so-called Nod factors (lipochitooligosaccharides), which lead to root hair curling and trapping of bacterial colonies as well as to growth and reprogramming of root cortex cells, finally leading to the formation of a nodule [5]. Commonly through infection threads, rhizobia penetrate the deeper plant tissue and are released intracellularly and surrounded by a symbiosome membrane. Inside plant cells, they differentiate into nitrogen-fixing bacteroids $[13,14]$. The oxygen concentration inside nodules is roughly $11 \mathrm{nM}$, which corresponds to a 10,000-fold lower concentration compared to aerobic conditions $[14,15]$. This oxygen-limited environment is important to protect nitrogenase activity and thereby initiate the expression of nitrogen fixation (nif) genes [14,16]. In diazotrophic bacteria and in P. phymatum, the sigma factor RpoN (or sigma-54) and its enhancer binding protein NifA have been shown to be essential for activation of nif gene expression and nitrogenase activity [17-19]. NifA activity is oxygensensitive due to the presence of conserved cysteine residues, which sense the oxygen level and allow the protein to assume its active form inside the nodules. The regulon of NifA was determined in several diazotrophs mainly using transcriptome and proteome analysis [20-25]. However, so far no study has described the NifA regulon in beta-rhizobia. We previously showed that plants inoculated with a P. phymatum nifA mutant were not only deficient in reducing atmospheric nitrogen, but also showed an increased number of nodules and displayed a grape-shaped structure on the roots [18].

Here, we successfully integrate metabolomics with dual RNA-Sequencing of Phaseolus vulgaris root nodules infected by a $P$. phymatum nifA mutant or by the wildtype. Using this strategy, we were able to assign metabolomics changes to the bacterium (P. phymatum) or to the plant host (P. vulgaris) and thereby discovered that P. phymatum NifA is not only a master regulator of genes involved in nitrogen fixation but also controls other potentially important symbiotic traits and induces substantial changes in the plant host. Together, this study illustrates the value of combing metabolomics with a dual RNA-Seq approach to tackle the biology of intracellular rhizobium-plant symbiotic interactions.

\section{Results and Discussion}

\subsection{Metabolomics Analysis of Nodules Infected by a nifA Mutant Strain}

In order to compare the metabolic status of the nodules occupied by either wildtype and nifA mutant strain, a non-targeted metabolomics analysis was performed on common bean nodules ( 21 days post infection) as described in the material and methods section. Overall, 526 metabolites could be identified, of which 172 showed differential levels in the nifA mutant versus wild-type nodules (Supplementary Table S1). Most of these (107) showed a decreased amount in nodules formed by the nifA mutant and approximately a fourth of them (24) were previously shown to be specifically accumulating in nodules formed by P. phymatum wild-type compared to uninoculated roots [26]. The absence of NifA in nodules was associated with a reduction of the content of the amino acids alanine, glycine, proline and tyrosine, threonine, glutamine, asparagine, lysine, glutamate and ornithine (Figure 1a). Several amino acid precursors showed also lowered levels in nodules infected by the nifA mutant, which suggests a reduced assimilation of nitrogen: 3-dehydroquinate and chorismate (tyrosine bioynthesis), phosphohomoserine (synthesis of threonine and glycine), aminoadipate and homocitrate (lysine biosynthesis), L-glutamyl 5-phosphate (synthesis of proline) and oxoglutarate, $\mathrm{N}$-acetyl-glutamate and $\mathrm{N}$-acetyl-ornithine. Aspartate was the only amino acid that was increased in nodules occupied by the nifA mutant. Moreover, the level of phosphoaspartate also increased in Fix $^{-}$nodules. For the tryptophan metabolic pathway, we observed an accumulation of formyl-anthranilate and a decreased amount of anthranilate. Sinorhizobium meliloti Rmd201 
anthranilate synthase $(\operatorname{tr} p E)$ mutants have been shown to be ineffective in nitrogenase activity inside alfalfa root nodules $[27,28]$. The one-carbon and purine biosynthesis intermediate 10 -formyl-tetrahydrofolate was less abundant in nodules occupied by the nif $A$ mutant. The level of the $\mathrm{C}_{4}$-dicarboxylate succinate decreased significantly in the non-fixing nodules containing the nifA mutant compared to wild-type nodules, reaching similar levels to uninfected roots (Figure 2). Succinate together with arginine (which also showed decreased levels in nifA nodules) is one of the major carbon supplies that the host plant offers to the bacteroids in exchange for ammonia [29]. Therefore, the plant may sanction the Fix ${ }^{-}$ bacteroids by interrupting carbon supply. On the other hand, the level of other compounds involved in glyoxylate and dicarboxylate metabolism, glycolate, oxalate and hydroxypyruvate as well as the important intermediate in carbon metabolism phosphoenolpyruvate (PEP) was higher in nodules infected by the nifA mutant relative to wild-type nodules. Interestingly, the higher oxalate level in nodules occupied by the nifA mutant (Figure 2) may indicates that-similarly to Bradyrhizobium efficiens [30]—P. phymatum is able to use oxalate as carbon and energy source. Indeed, a genomic inspection in P. phymatum genome revealed the presence of the key pathway genes oxc (for oxalyl-coenzyme A decarboxylase) and frc (for formyl-coenzyme A transferase). However, these genes were not differentially expressed in wild-type and mutant nodules (see below). Two products of nitrogen fixation known to be assimilated in determinate common bean nodules, allantoin and allantoate, as well as their precursors hydroxyisourate and the purine guanine showed reduced levels in nodules infected by the nifA mutant. GTP and the allantoate precursor inosine showed the opposite trend, i.e., accumulation in non-fixing nodules.

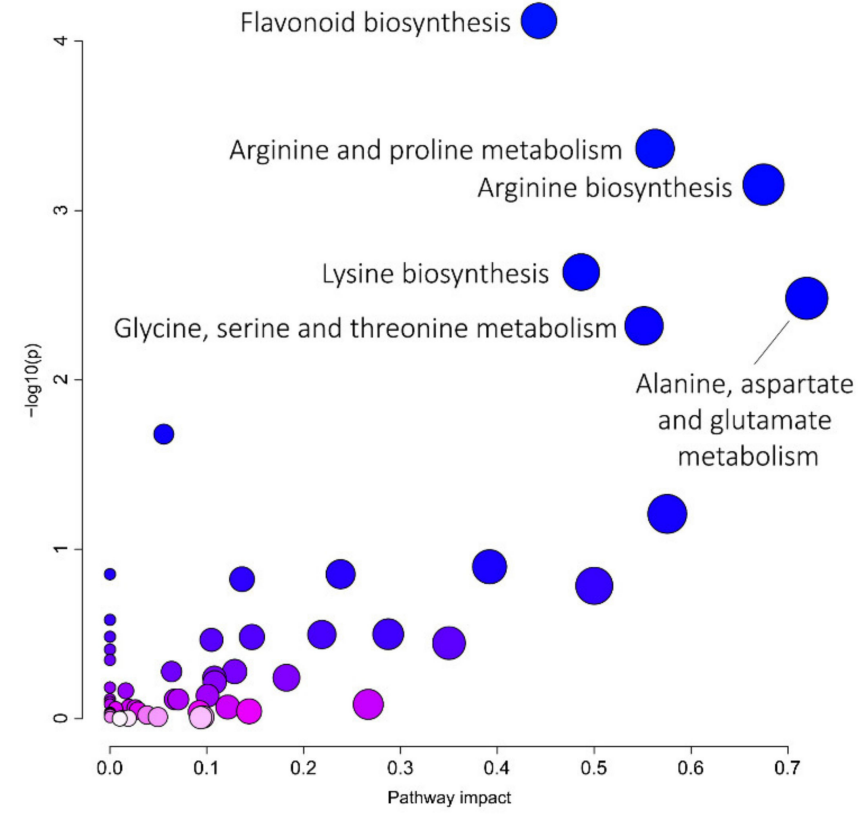

(a)

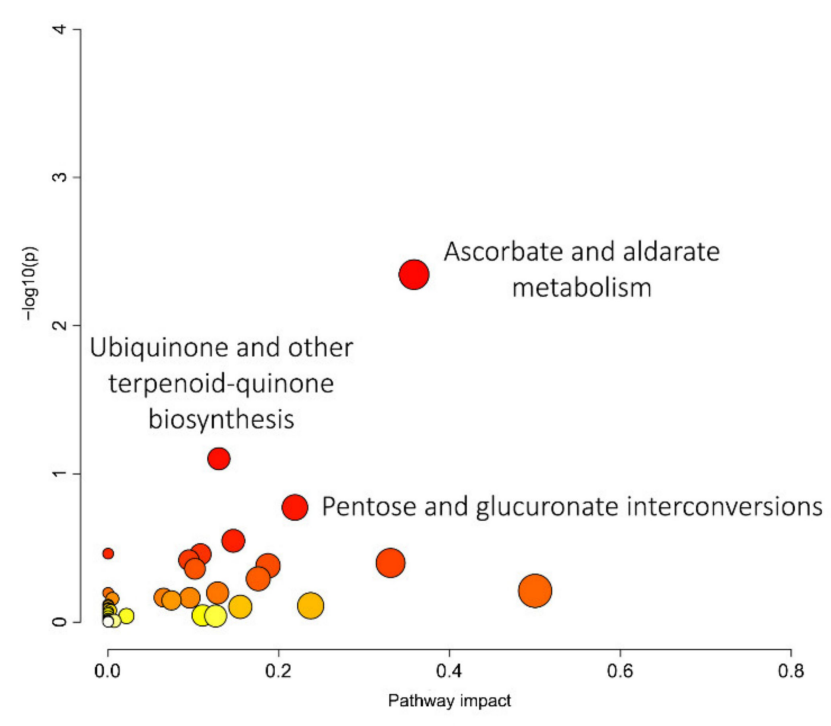

(b)

Figure 1. KEGG metabolic pathway enrichment and pathway topology analysis. Over-represented KEGG metabolic pathways in bean nodules colonized by P. phymatum wild-type compared to nodules colonized by P. phymatum nifA mutant (a) and over-represented in nifA compared to wild-type nodules (b). The metabolites used for this representation display different levels in both types of nodules (absolute $\log _{2} \mathrm{FC}<0.5$ and $q$-values $\leq 0.01$ ). 


\section{Succinate}

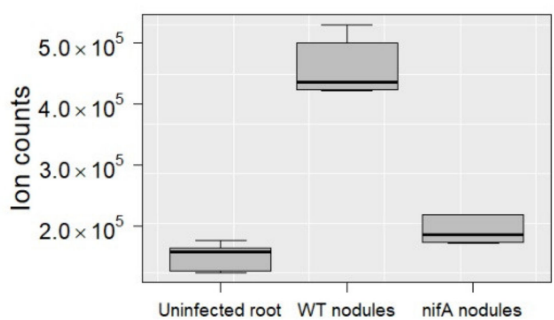

Glutamine

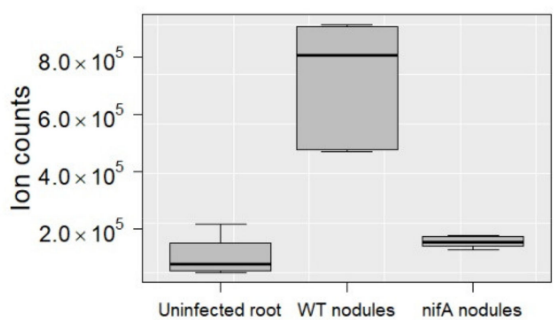

Tryptophan

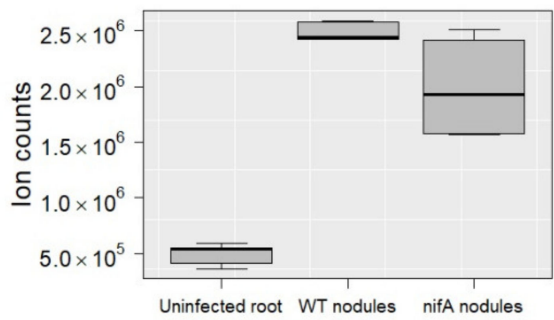

Brassinolide

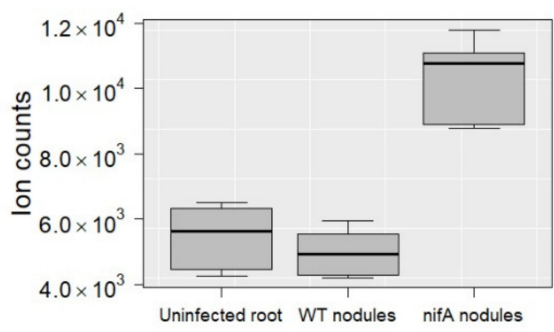

Naringenin

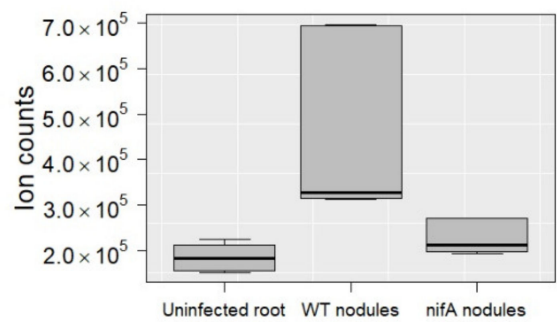

Oxalic acid

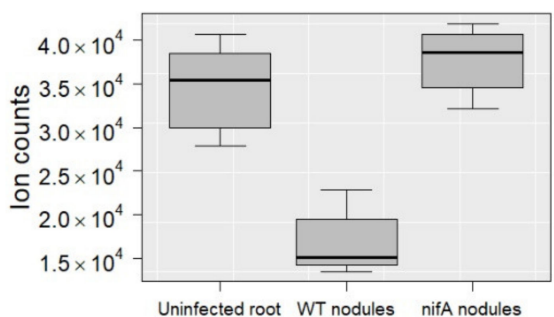

Glutamate

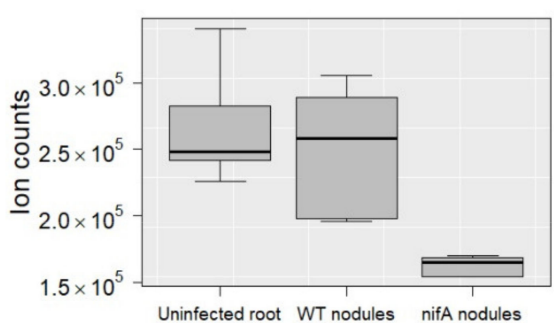

Indole-acetamide

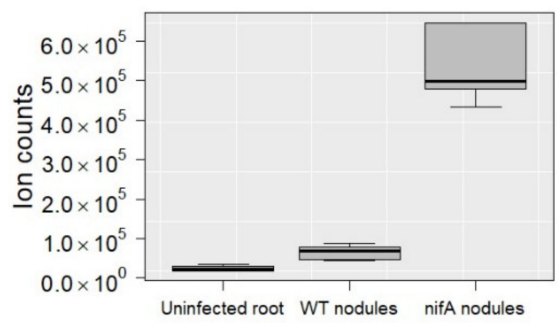

5,7,24(28)-Ergostatrienol

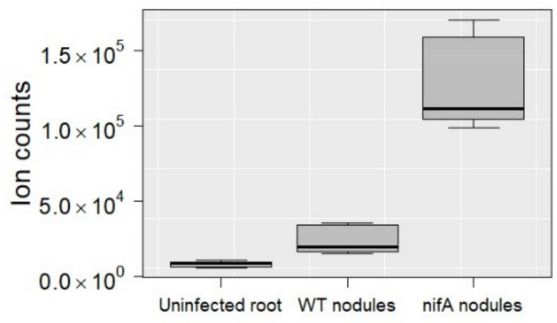

(-)-Vestitol

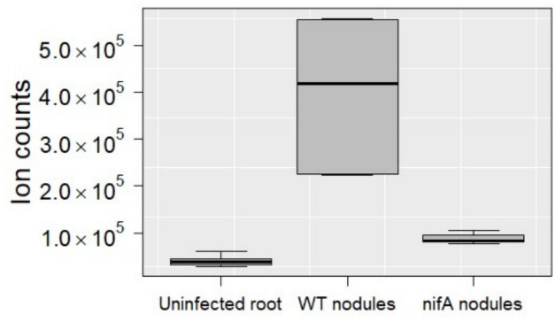

Figure 2. Comparison of the ion counts detected for each metabolite in uninfected bean roots (Uninfected root), nodules infected with P. phymatum wild-type (WT nodules) and nodules infected with P. phymatum nifA mutant (nifA nodules). The following compounds were examined: succinate, oxalic acid, glutamine, glutamate, tryptophan, indole-acetamide, brassinolide, 5,7,24(28)-ergostatrienol, naringenin and (-)-vestitol. Three biological replicates with two technical replicates were analyzed and are shown as boxplots (median in bold). 
Among the metabolites showing decreased levels in nodules infected by the nif $A$ mutant we found catechol and cyclohexanone, which are intermediates in the degradation of aromatic compounds. Several flavonoids and isoflavonoids were also found among the metabolites less accumulated in nif $A$ mutant nodules (putatively assigned to naringenin, luteolin, (-)-vestitone, (-)-vestitol, 3,9-dihydroxypterocarpan, biochanin A) (Figure 1a). Since flavonoids are important signals used by the plants to communicate with their rhizobial partners [31,32], we speculate that in nodules occupied by the nif $A$ mutant, the communication between bacteria and plant may be impaired. Moreover, flavonoids are recognized auxin transport inhibitors, which could affect plant growth [33]. The level of flavonoids such as naringenin and (-)-vestitol in nodules occupied by the nifA mutant was reduced to similar levels detected in uninfected roots (Figure 2). In contrast, several compounds involved in steroid and brassinosteroid biosynthesis were among the 65 compounds accumulating in bean nodules occupied by the nifA mutant (Figure 1b). Brassinosteroids (BR) are plant hormones, which promote cell division [34] and inhibit infection thread formation [35]. They have been shown to interact with auxin leading to its accumulation in the cortical tissue [36]. Indeed, the most highly accumulated metabolite in nodules occupied by the nifA mutant was the auxin indole-acetamide (IAM) (Supplementary Table S1, Figure 2). Another auxin, the well-investigated indole-3-acetic acid (IAA) was found to be 1.4-fold increased, although the difference with wild-type nodules was not considered as significant with the thresholds we applied $\left(\log _{2}\right.$ fold change $\geq 0.5$ and $q$-value $\leq 0.01$ ). Auxins play multiple roles in plants and accumulate in infected root hairs, facilitating infection-thread formation during Mesorhizobium loti-Lotus japonicus symbiosis [37]. The increase in auxins is in agreement with a slight decrease in tryptophan (Figure 2), the precursor of auxins, suggesting that the observed accumulation of auxins occurred via the tryptophan-dependent pathway. Without further microscopic investigations, it is premature to interpret the impact of the imbalanced BR/auxin homeostasis and flavonoids contents on the organogenesis and development of nifA-colonized nodules. In contrast to indeterminate nodules, hormonal cross-talks and flavonoids regulation are less described in determinate nodules. However, genetic work in M. truncatula suggested BR as $\mathrm{AON}$-independent promoters of nodule number, and the role of auxins in specifying nodule founder cells and the progression of nodule growth is well-established [38,39].

\subsection{RNA-Sequencing and P. phymatum Differential Gene Expression}

After mapping the reads to P. phymatum genome, we observed 479 bacterial genes to be differentially expressed (Supplementary Table S2, see Material and Methods, Section 3.4) in 21 days post infection (dpi) nodules infected by the wild-type or the nif $A$ mutant strain. Out of the 479 rhizobial genes, 142 (roughly $30 \%$ ) were located on the symbiotic plasmid pBPHY02, confirming the importance of this transcriptional regulator during symbiosis (Table 1).

Table 1. List of the 142 genes located in P. phymatum STM815 symbiotic plasmid (pBPHY02) that showed a differential expression in common bean nodules infected with nif $A$ mutant strain compared to the wild-type nodules (abs[ $\log _{2}$ (foldchange) $] \geq 0.5$ and $p$-value $\leq 0.02$ ).

\begin{tabular}{|c|c|c|c|c|}
\hline Locus ID $^{1}$ & Description $^{1}$ & Old Locus ID ${ }^{1}$ & Gene Name $^{1}$ & $\begin{array}{c}\log _{2} \mathrm{FC} \\
(\text { nifA vs. wt })^{2}\end{array}$ \\
\hline \multicolumn{5}{|c|}{ Genes up-regulated in nifA mutant bacteroids } \\
\hline BPHY_RS41160 & hypothetical protein & Bphy_7816 & & 4.47 \\
\hline BPHY_RS38115 & hypothetical protein & Bphy_7726 & & 2.53 \\
\hline BPHY_RS38105 & ATP-grasp domain-containing protein & Bphy_7724 & & 2.26 \\
\hline BPHY_RS36585 & DNA-binding protein & Bphy_7384 & & 2.24 \\
\hline BPHY_RS38320 & indoleacetamide hydrolase & Bphy_7768 & $i a a H$ & 1.69 \\
\hline \multicolumn{5}{|c|}{ Genes down-regulated in nif $A$ mutant bacteroids } \\
\hline BPHY_RS37800 & $\begin{array}{l}\text { branched-chain amino acid ABC transporter } \\
\text { substrate-binding protein }\end{array}$ & Bphy_7652 & & -2.10 \\
\hline
\end{tabular}


Table 1. Cont.

\begin{tabular}{|c|c|c|c|c|}
\hline Locus ID $^{1}$ & Description ${ }^{1}$ & Old Locus ID ${ }^{1}$ & Gene Name ${ }^{1}$ & $\begin{array}{c}\log _{2} \mathrm{FC} \\
(\text { nifA vs. wt })^{2}\end{array}$ \\
\hline BPHY_RS37125 & GntR family transcriptional regulator & Bphy_7505 & & -2.18 \\
\hline BPHY_RS37205 & hypothetical protein & Bphy_7521 & & -2.25 \\
\hline BPHY_RS37050 & biosynthetic-type acetolactate synthase large subunit & Bphy_7490 & $i l v B$ & -2.27 \\
\hline BPHY_RS37120 & $\mathrm{ABC}$ transporter substrate-binding protein & Bphy_7504 & & -2.32 \\
\hline BPHY_RS38545 & iron-sulfur cluster assembly accessory protein & Bphy_7815 & & -2.33 \\
\hline BPHY_RS38560 & porin & Bphy_7819 & & -2.47 \\
\hline BPHY_RS37795 & $\begin{array}{l}\text { aminotransferase class III-fold pyridoxal } \\
\text { phosphate-dependent enzyme }\end{array}$ & Bphy_7651 & & -2.51 \\
\hline BPHY_RS37925 & hypothetical protein & Bphy_7682 & & -2.52 \\
\hline BPHY_RS37805 & IS630 family transposase & Bphy_7653 & & -2.57 \\
\hline BPHY_RS37025 & DMT family transporter & Bphy_7485 & & -2.58 \\
\hline BPHY_RS38285 & carbon starvation protein $\mathrm{A}$ & Bphy_7759 & & -2.62 \\
\hline BPHY_RS37790 & M81 family peptidase & Bphy_7649 & & -2.71 \\
\hline BPHY_RS37915 & hypothetical protein & Bphy_7680 & & -2.84 \\
\hline BPHY_RS41075 & hypothetical protein & Bphy_7694 & & -2.95 \\
\hline BPHY_RS37775 & ABC transporter permease & Bphy_7646 & & -3.00 \\
\hline BPHY_RS36465 & hypothetical protein & Bphy_7358 & & -3.01 \\
\hline BPHY_RS37930 & hypothetical protein & & & -3.13 \\
\hline BPHY_RS38520 & nitrogenase molybdenum-iron protein alpha chain & Bphy_7809 & & -3.16 \\
\hline BPHY_RS37765 & $\mathrm{ABC}$ transporter substrate-binding protein & Bphy_7644 & & -3.16 \\
\hline BPHY_RS38135 & $\begin{array}{l}\text { nitrogenase iron-molybdenum cofactor biosynthesis } \\
\text { protein }\end{array}$ & Bphy_7730 & nifN & -3.16 \\
\hline BPHY_RS37090 & pyridoxal-phosphate dependent enzyme & Bphy_7498 & & -3.19 \\
\hline BPHY_RS41155 & hypothetical protein & Bphy_7814 & & -3.27 \\
\hline BPHY_RS41070 & cytolethal distending toxin subunit B family protein & Bphy_7691 & & -3.30 \\
\hline BPHY_RS37780 & $\mathrm{ABC}$ transporter ATP-binding protein & Bphy_7647 & & -3.40 \\
\hline BPHY_RS40855 & IS110 family transposase & Bphy_7484 & & -3.40 \\
\hline BPHY_RS37770 & $\mathrm{ABC}$ transporter permease & Bphy_7645 & & -3.49 \\
\hline BPHY_RS37045 & ISL3 family transposase & Bphy_7489 & & -3.60 \\
\hline BPHY_RS37920 & hypothetical protein & Bphy_7681 & & -3.62 \\
\hline BPHY_RS38485 & $\begin{array}{l}\text { electron transfer flavoprotein subunit alpha/FixB family } \\
\text { protein }\end{array}$ & Bphy_7803 & fix $B$ & -3.63 \\
\hline BPHY_RS41535 & IS3 family transposase & & & -3.63 \\
\hline BPHY_RS36015 & $\begin{array}{l}\text { HyaD/HybD family hydrogenase maturation } \\
\text { endopeptidase }\end{array}$ & Bphy_7262 & $h y b D$ & -3.70 \\
\hline BPHY_RS36485 & hypothetical protein & & & -3.83 \\
\hline BPHY_RS41135 & electron transfer flavoprotein alpha/beta-subunit & Bphy_7804 & & -3.90 \\
\hline BPHY_RS36645 & alpha/beta fold hydrolase & Bphy_7397 & & -3.91 \\
\hline BPHY_RS38310 & cytochrome P450 & Bphy_7766 & & -4.00 \\
\hline BPHY_RS40820 & IS5/IS1182 family transposase & & & -4.06 \\
\hline BPHY_RS38020 & radical SAM protein & Bphy_7706 & & -4.07 \\
\hline BPHY_RS37785 & $\mathrm{ABC}$ transporter ATP-binding protein & Bphy_7648 & & -4.10 \\
\hline BPHY_RS37970 & 7-carboxy-7-deazaguanine synthase QueE & Bphy_7690 & & -4.11 \\
\hline BPHY_RS37005 & GntR family transcriptional regulator & Bphy_7481 & & -4.44 \\
\hline BPHY_RS36735 & $\begin{array}{c}\text { ArgP/LysG family DNA-binding transcriptional } \\
\text { regulator }\end{array}$ & Bphy_7420 & & -4.51 \\
\hline BPHY_RS37085 & Lrp/AsnC family transcriptional regulator & Bphy_7497 & & -4.58 \\
\hline BPHY_RS38495 & FAD-binding oxidoreductase & Bphy_7805 & & -4.62 \\
\hline BPHY_RS36730 & sodium:solute symporter & Bphy_7419 & & -4.66 \\
\hline BPHY_RS35975 & carbamoyltransferase & Bphy_7254 & hypF & -4.74 \\
\hline BPHY_RS38270 & hypothetical protein & & & -4.78 \\
\hline BPHY_RS37910 & IS6 family transposase & Bphy_7679 & & -4.80 \\
\hline BPHY_RS36725 & fatty acid desaturase & Bphy_7418 & & -4.87 \\
\hline BPHY_RS38515 & nitrogenase iron protein & Bphy_7808 & nifH & -4.88 \\
\hline BPHY_RS36010 & $\begin{array}{c}\text { HypC/HybG/HupF family hydrogenase formation } \\
\text { chaperone }\end{array}$ & Bphy_7261 & hypC & -4.95 \\
\hline BPHY_RS38025 & glycosyltransferase & Bphy_7707 & & -4.98 \\
\hline
\end{tabular}


Table 1. Cont.

\begin{tabular}{|c|c|c|c|c|}
\hline Locus ID $^{1}$ & Description $^{1}$ & Old Locus ID ${ }^{1}$ & Gene Name ${ }^{1}$ & $\begin{array}{c}\log _{2} \mathrm{FC} \\
(\text { nifA vs. wt })^{2}\end{array}$ \\
\hline BPHY_RS38365 & putative nitrogen fixation protein & Bphy_7777 & nifT & -5.01 \\
\hline BPHY_RS35985 & hydrogenase maturation nickel metallochaperone & Bphy_7256 & hypA & -5.14 \\
\hline BPHY_RS37115 & histidine $\mathrm{ABC}$ transporter permease & Bphy_7503 & hisQ & -5.14 \\
\hline BPHY_RS38425 & class I SAM-dependent methyltransferase & Bphy_7790 & & -5.14 \\
\hline BPHY_RS36060 & hydrogenase expression/formation protein & Bphy_7271 & hypE & -5.17 \\
\hline BPHY_RS37065 & porin & Bphy_7493 & & -5.33 \\
\hline BPHY_RS38140 & nitrogen fixation protein & Bphy_7731 & nifX & -5.35 \\
\hline BPHY_RS36005 & hydrogenase & Bphy_7260 & hyaE & -5.43 \\
\hline BPHY_RS36050 & hypothetical protein & & & -5.51 \\
\hline BPHY_RS36020 & $\mathrm{Ni} / \mathrm{Fe}$-hydrogenase, b-type cytochrome subunit & Bphy_7263 & $c y b H$ & -5.63 \\
\hline BPHY_RS36740 & SDR family oxidoreductase & Bphy_7421 & & -5.68 \\
\hline BPHY_RS40825 & glutamine amidotransferase class-II & Bphy_7471 & & -5.75 \\
\hline BPHY_RS38160 & hypothetical protein & Bphy_7735 & & -5.82 \\
\hline BPHY_RS37075 & hypothetical protein & Bphy_7495 & & -5.83 \\
\hline BPHY_RS37110 & histidine $A B C$ transporter permease & Bphy_7502 & hisM & -5.83 \\
\hline BPHY_RS41065 & cupin & Bphy_7689 & & -5.83 \\
\hline BPHY_RS38225 & hypothetical protein & Bphy_7748 & & -5.88 \\
\hline BPHY_RS38130 & $\begin{array}{l}\text { nitrogenase iron-molybdenum cofactor biosynthesis } \\
\text { protein }\end{array}$ & Bphy_7729 & nifE & -5.89 \\
\hline BPHY_RS37735 & NAD-dependent epimerase/dehydratase family protein & Bphy_7636 & & -5.92 \\
\hline BPHY_RS41080 & AraC family transcriptional regulator & Bphy_7704 & & -5.92 \\
\hline BPHY_RS37080 & MmgE/PrpD family protein & Bphy_7496 & & -5.97 \\
\hline BPHY_RS37105 & ATP-binding cassette domain-containing protein & Bphy_7501 & & -6.13 \\
\hline BPHY_RS36745 & histidinol dehydrogenase & Bphy_7422 & his $D$ & -6.13 \\
\hline BPHY_RS36000 & hydrogenase expression/formation protein & Bphy_7259 & & -6.16 \\
\hline BPHY_RS35990 & HupK protein & Bphy_7257 & hupK & -6.18 \\
\hline BPHY_RS41530 & transposase & Bphy_7402 & & -6.22 \\
\hline BPHY_RS37965 & class I SAM-dependent methyltransferase & Bphy_7688 & & -6.25 \\
\hline BPHY_RS36055 & cysteine hydrolase & Bphy_7270 & & -6.29 \\
\hline BPHY_RS37070 & $\mathrm{ABC}$ transporter substrate-binding protein & Bphy_7494 & & -6.33 \\
\hline BPHY_RS40990 & IS5/IS1182 family transposase & Bphy_7635 & & -6.34 \\
\hline BPHY_RS37100 & aminopeptidase $\mathrm{P}$ family protein & Bphy_7500 & & -6.59 \\
\hline BPHY_RS38155 & nitrogen fixation protein & Bphy_7734 & nifQ & -6.59 \\
\hline BPHY_RS35995 & [NiFe]-hydrogenase assembly, chaperone & Bphy_7258 & $h y b E$ & -6.61 \\
\hline BPHY_RS41545 & FAD-dependent oxidoreductase & & & -6.68 \\
\hline BPHY_RS41140 & hypothetical protein & Bphy_7806 & & -6.82 \\
\hline BPHY_RS41095 & hypothetical protein & Bphy_7746 & & -6.85 \\
\hline BPHY_RS39040 & pyridoxal-phosphate dependent enzyme & Bphy_7479 & & -6.85 \\
\hline BPHY_RS38150 & ferredoxin III, nif-specific & Bphy_7733 & $f d x B$ & -6.86 \\
\hline BPHY_RS36650 & IS5/IS1182 family transposase & Bphy_7398 & & -6.90 \\
\hline BPHY_RS36025 & nickel-dependent hydrogenase large subunit & Bphy_7264 & & -6.96 \\
\hline BPHY_RS38145 & hypothetical protein & Bphy_7732 & & -7.01 \\
\hline BPHY_RS38245 & ankyrin repeat domain-containing protein & Bphy_7751 & & -7.11 \\
\hline BPHY_RS38170 & protein FixC & Bphy_7737 & $f i x C$ & -7.11 \\
\hline BPHY_RS37030 & ISL3 family transposase & Bphy_7486 & & -7.17 \\
\hline BPHY_RS37740 & SDR family NAD(P)-dependent oxidoreductase & Bphy_7637 & & -7.21 \\
\hline BPHY_RS38230 & IS630 family transposase & Bphy_7749 & & -7.34 \\
\hline BPHY_RS38255 & nitrogenase iron protein & Bphy_7753 & nifH & -7.40 \\
\hline BPHY_RS36670 & aldehyde dehydrogenase family protein & Bphy_7406 & & -7.41 \\
\hline BPHY_RS38525 & LysR family transcriptional regulator & Bphy_7810 & & -7.42 \\
\hline BPHY_RS36065 & carbamoyltransferase & Bphy_7272 & hypF & -7.47 \\
\hline BPHY_RS36035 & hypothetical protein & & & -7.51 \\
\hline BPHY_RS36675 & maltose alpha-D-glucosyltransferase & Bphy_7407 & tres & -7.53 \\
\hline BPHY_RS38220 & putative nitrogen fixation protein & Bphy_7747 & nifT & -7.55 \\
\hline BPHY_RS36040 & diaminobutyrate-2-oxoglutarate transaminase & Bphy_7266 & ect $B$ & -7.58 \\
\hline BPHY_RS38265 & nitrogenase molybdenum-iron protein subunit beta & Bphy_7755 & nifK & -7.67 \\
\hline BPHY_RS38240 & zinc ribbon domain-containing protein & Bphy_7750 & & -7.72 \\
\hline
\end{tabular}


Table 1. Cont.

\begin{tabular}{|c|c|c|c|c|}
\hline Locus ID $^{1}$ & Description $^{1}$ & Old Locus ID ${ }^{1}$ & Gene Name ${ }^{1}$ & $\begin{array}{c}\log _{2} \mathrm{FC} \\
(\text { nifA vs. wt) }\end{array}$ \\
\hline BPHY_RS38185 & nitrogenase stabilizing/protective protein & Bphy_7740 & nifW & -7.78 \\
\hline BPHY_RS36655 & group II intron reverse transcriptase/maturase & Bphy_7399 & $\operatorname{lt} A$ & -7.78 \\
\hline BPHY_RS36045 & GNAT family N-acetyltransferase & Bphy_7268 & & -8.06 \\
\hline BPHY_RS40995 & IS5/IS1182 family transposase & Bphy_7638 & & -8.07 \\
\hline BPHY_RS37730 & multi anti extrusion protein & Bphy_7634 & matE & -8.21 \\
\hline BPHY_RS37000 & ISL3 family transposase & Bphy_7480 & & -8.22 \\
\hline BPHY_RS36990 & GHMP kinase & Bphy_7478 & & -8.24 \\
\hline BPHY_RS38190 & homocitrate synthase & Bphy_7741 & nifV & -8.28 \\
\hline BPHY_RS37725 & D-alanine-D-alanine ligase & Bphy_7633 & & -8.45 \\
\hline BPHY_RS38165 & ferredoxin & Bphy_7736 & fix $X$ & -8.93 \\
\hline BPHY_RS38175 & $\begin{array}{c}\text { electron transfer flavoprotein subunit alpha/FixB family } \\
\text { protein }\end{array}$ & Bphy_7738 & fixB & -9.16 \\
\hline BPHY_RS36680 & ABC transporter ATP-binding protein & Bphy_7408 & & -9.33 \\
\hline BPHY_RS38195 & nitrogenase cofactor biosynthesis protein & Bphy_7742 & nifB & -9.83 \\
\hline BPHY_RS38260 & nitrogenase molybdenum-iron protein alpha chain & Bphy_7754 & nifD & -10.05 \\
\hline BPHY_RS36030 & $\begin{array}{l}\text { twin-arginine translocation signal domain-containing } \\
\text { protein }\end{array}$ & Bphy_7265 & hydA & -10.25 \\
\hline BPHY_RS38180 & $\begin{array}{c}\text { electron transfer flavoprotein beta subunit/FixA family } \\
\text { protein }\end{array}$ & Bphy_7739 & fixA & -10.52 \\
\hline BPHY_RS38505 & hypothetical protein & Bphy_7807 & & -11.11 \\
\hline BPHY_RS38250 & hypothetical protein & Bphy_7752 & & -11.54 \\
\hline BPHY_RS40755 & IS66 family transposase & Bphy_7404 & & NA \\
\hline BPHY_RS37010 & IS3 family transposase & Bphy_7482 & & NA \\
\hline BPHY_RS36905 & glycolate oxidase subunit $G$ & Bphy_7454 & $g l c D$ & NA \\
\hline BPHY_RS41325 & diaminobutyrate-2-oxoglutarate transaminase & Bphy_7273 & & NA \\
\hline BPHY_RS38360 & nitrogen fixation protein & Bphy_7776 & nifZ & NA \\
\hline BPHY_RS37060 & hypothetical protein & & & NA \\
\hline BPHY_RS38235 & hypothetical protein & & & NA \\
\hline BPHY_RS35970 & $\begin{array}{c}\text { HypC/HybG/HupF family hydrogenase formation } \\
\text { chaperone }\end{array}$ & Bphy_7253 & hypC & NA \\
\hline BPHY_RS38210 & nitrogen fixation protein & Bphy_7745 & nifZ & NA \\
\hline BPHY_RS40615 & hypothetical protein & Bphy_7267 & & NA \\
\hline BPHY_RS40750 & hypothetical protein & & & NA \\
\hline
\end{tabular}

${ }^{1}$ Locus tag, gene description, old locus tag and gene name is given according to the RefSeq files (NC_010622.1, NC_010623.1, NC_010625.1, NC_010627.1); ${ }^{2} \log _{2}$ Fold Change (FC) of transcriptional level, comparing nifA mutant with wild-type strain nodules; NA, the read number of the nifA nodules was 0. ATP, Adenosine Tri-Phosphate; ABC, ATP-Binding Cassette; IS, Insertion Sequence; DMT, Drug/Metabolite Transporter; SAM, S-Adenosyl Methionine; SDR, Short-Chain Dehydrogenase Reductase; FAD, Flavin Adenine Dinucleotide; NAD(P), Nicotinamide adenine dinucleotide phosphate; GNAT, Gcn5-related N-acetyltransferases.

Among the 367 genes showing down-regulation in the nifA mutant, we found several nif and hyp genes, coding for nitrogenase and hydrogenase-related genes. Consistent with a decrease in homocitrate levels, the expression of the P. phymatum homocitrate synthase encoding gene nifV (Bphy_7741) was down-regulated in nodules in absence of NifA. We recently showed that NifV is crucial for nitrogenase function during free-living growth and during symbiosis with papilionoid plants [26]. Moreover, the cytochrome o ubiquinol oxidase (Bphy_3649-46, cyoABCD), which we previously identified to be important for P. phymatum symbiosis with common bean, was also among the top genes positively regulated by NifA [18]. In line with the decrease in glutamine observed in our metabolomics analysis (Figure 2), we found Bphy_6981 coding for a glutamine synthetase to be down-regulated in nifA mutant bacteroids (Supplementary Figure S1a). Furthermore, Bphy_5298 and Bphy_7471, coding for a glutamine amidotransferase class I and class II, respectively, showed decreased expression in nifA bacteroids. Glutamine amidotransferases are involved in nitrogen assimilation and generate ammonia by glutamine hydrolysis, which is then transferred to a specific substrate. Congruent with the downregulation of the pyridoxal-phosphate dependent enzyme encoded by Bphy_7498 that converts o-phospho-L homoserine into threonine, we found a decrease of both compounds 
in nodules occupied by a nifA mutant. The decreased expression of Bphy_5639 encoding an aspartate ammonia-lyase (AspA) that converts aspartate into the $\mathrm{C}_{4}$-dicarboxylate fumarate, may explain the accumulation of aspartate in nodules infected by the nif $A$ mutant (Supplementary Figure S1a). Moreover, the decrease of L-aspartate-4-semialdehyde and 2,4 diaminobutanoate could be connected to the down-regulation of the Bphy_7266 (ectB) transcript coding for a diaminobutyrate-2-oxoglutarate transaminase. The operon Bphy_7504-01 coding for a potential lysine/arginine/ornithine ABC transporter located on the symbiotic plasmid was down-regulated and reflected the decrease of the metabolites lysine and ornithine in nifA bacteroids (Figure 3a). Another operon (Bphy_7232-37) located on $\mathrm{PBPHY} 01$ encoding a potential alkane sulfonate $\mathrm{ABC}$ transporter showed less expression in a nifA mutant compared to the wild-type during symbiosis (Figure $3 \mathrm{~b}$ ). An ABC transporter-like protein for transport of branched amino acids (Bphy_3041) was down-regulated at the transcript level. The two-component regulatory system NarXL (Bphy_6191/6192) as well as the two nitrate reductase genes narG and narH showed decreased expression in nodules occupied by the nifA mutant, suggesting that NifA is involved in the control of nitrate metabolism in bacteroids. In addition to the previously mentioned alkane sulfonate $\mathrm{ABC}$ transporter, expression of several other genes involved in sulfur metabolism was down-regulated in the nif $A$ mutant compared to wild-type bacteroids. For example, the sulfite dehydrogenase complex SoxCD (Bphy_7230-31), a potential taurine transporter (Bphy_6080/81), the sulfurtransferase Bphy_6245 converting thiosulfate into sulfite, Bphy_2231 coding for a sulfate adenylyltransferase, Bphy_3604 encoding a TauD/TfdA family dioxygenase, which potentially converts taurine into sulfite, and Bphy_7479 potentially involved in producing cysteine from sulfide. Additionally, cysN (Bphy_2231), coding for a sulfate adenylyltransferase was also down-regulated in bacteroids missing nifA. The expression of treS (Bphy_7407) coding for a trehalose synthase was decreased in nifA mutant bacteroids compared to wild-type bacteroids. However, our metabolomics data showed the amount of trehalose did not change in nifA nodules compared to wild-type nodules. Among the down-regulated genes we also found one potential ferritin (Bphy_1509) that are known to confer protection against oxidative stress by oxidizing ferrous ions $\left(\mathrm{Fe}^{2+}\right)$ to ferric ions $\left(\mathrm{Fe}^{3+}\right)[40]$.

(a)

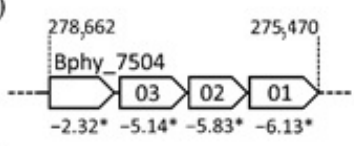

(b)

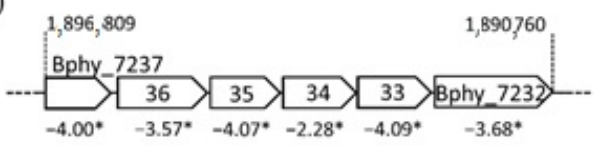

(c)

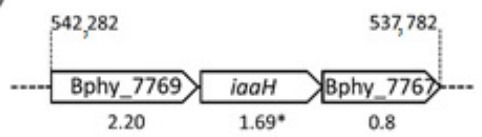

(d)

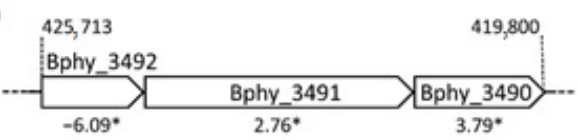

(e)

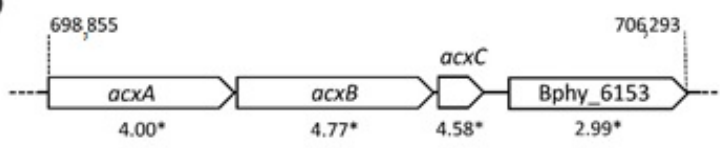

(f)

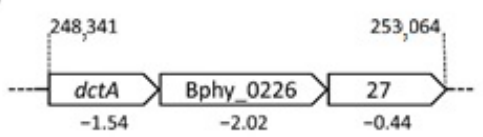

Figure 3. A selection of P. phymatum operons showing differential expression in nifA nodules compared to wild-type nodules. The following operons are represented: (a) lysine/arginine/ornithine ABC transporter; (b) alkane sulfonate ABC transporter; (c) indole-3-acetic acid synthesis (iaa); (d) efflux RND transporter; (e) acetone carboxylase (acx); (f) dicarboxylate symporter $(d c t)$. The genomic coordinates according to the replicon where the operon belongs are indicated at the beginning of the operon and gene names are indicated in italic. The $\log _{2} \mathrm{FC}$ values are shown underneath the operons, with statistically significant ones marked with an asterisk.

Among the 112 P. phymatum genes with up-regulated expression in nif $A$ mutant bacteroids, only five were located on the symbiotic plasmid: Bphy_7724 and Bphy_7726 coding for a putative biotin carboxylase and a hypothetical protein (HP) with a heme 
oxygenase domain, respectively; Bphy_7816 (HP), Bphy_7384 encoding a histone family protein DNA-binding protein and Bphy_7768 (iaaH) coding for an indole acetamide (IAM) hydrolase (Figure 3c) (Supplementary Figure S1b). The up-regulation of P. phymatum iaaH expression strongly suggests that the accumulated auxin in nodules infected with the nifA mutant is synthetized by the bacteria. Several genes involved in the response to stress showed increased expression in non-fixing bacteroids such as Bphy_2521 (catalase) and Bphy_3656 (alkyl hydroperoxide reductase subunit F), both involved in the reaction to oxidative stress, a protease with a HtrA/DegQ protease family signature (Bphy_0471) and Bphy_0301 coding for the RpoH sigma factor. RpoH has been discovered as the main regulator of the heat-shock response in E. coli thereby regulating transcription of genes coding for chaperones and proteases [41]. In addition to heat response, $\mathrm{RpoH}$ has been shown to play a role in oxidative stress response, for osmotic tolerance, virulence and during nitrogen-fixing symbiosis [42,43]. In contrast to alpha-rhizobial strains, which usually display two or three copies of $r p o H$ in their genome [44], P. phymatum possesses only this single copy. A Sinorhizobium meliloti $\mathrm{rpoH}_{1}$ mutant was able to nodulate alfalfa plants but failed to fix nitrogen inside nodules. Both $\mathrm{S}$. meliloti $r p o \mathrm{H}_{1}$ and $\mathrm{rpoH}_{2}$ copies were shown to be involved in the regulation of the expression of heat shock proteins. Curiously, P. phymatum RpoH showed higher homologies to S. meliloti $r p o H_{1}(42 \%$ identities, $61 \%$ similarities at the amino acid level). The up-regulation of transcripts involved in the stress response suggests that nif $A$ mutant bacteroids are stressed inside the nodule. Among the statistically significant up-regulated genes, several were organized in a predicted operon structure such as Bphy_3490-92 coding for an efflux RND transporter (Figure 3d), Bphy_4949-50 probably involved in fatty acid metabolism, Bphy_5790-92 containing a beta-lactamase domain-containing protein and a reductase, Bphy_6150-52 encoding a potential acetone carboxylase that catalyzes the condensation of acetone and $\mathrm{CO}_{2}$ to form acetoacetate in order to grow with acetone as carbon source and electron donor for respiration (Figure 3e). The acxABC operon in Helicobacter pylori has been shown to be important for colonization of the gastric mucosa and may therefore play a role in survival of the bacterium in the stomach [45]. Remarkably, the expression of the sigma-54dependent transcriptional regulatory gene Bphy_6153 located downstream of this operon was also increased in nodules occupied by the nifA mutant, suggesting that Bphy_6153 controls acetone carboxylase expression (Figure 3e). Moreover, two genes coding for two enzymes involved in the TCA cycle showed higher expression in nif $A$ nodules compared to wild-type nodules: Bphy_5588 encoding a succinate dehydrogenase flavoprotein subunit potentially converting succinate into fumarate and Bphy_4692 coding for a succinyl-CoA synthetase (Supplementary Figure S1a). Our metabolomics data showed that succinate and 2-oxoglutarate were less abundant in non-fixing nodules formed by the nif $A$ mutant compared to wild-type nodules, suggesting that nifA mutant bacteroids may try to provide itself energy and carbon sources.

\subsection{RNA-Sequencing and P. vulgaris Differential Gene Expression}

Out of the 1572 P. vulgaris differentially expressed genes (see Material and Methods, Section 3.4), 337 transcripts were found more abundant in nodules colonized by the nifA mutant (Supplementary Table S3). Apart from few putative defense-related genes, counting three diseases resistance-responsive (dirigent-like protein) family proteins, five protein kinases and three ABCG transporters, nif $A$ nodules do not present a strong immune response (Supplementary Table S4). A notable exception to this trend was the strong overexpression of the PATHOGENESIS-RELATED protein 1 (PR-1) family member PHAVU_006G196900g. PR-1 proteins represent common markers of the late, salicylic acid-driven pathogenic response [46]. Similarly, besides a WRKY transcription factor (PHAVU_004G105800g), a protein belonging to the ENHANCED DISEASE SUSCEPTIBILITY TO ERYSIPHE ORONTII family (PHAVU_010G011700g) and three disease resistance proteins (PHAVU_010G028700g, PHAVU_010G027300g and PHAVU_010G028800g), very few genes related to this functional category were found significantly down-regulated in nifA nodules compared to P. phymatum wild-type nodules. 
Interestingly, two NAD-dependent malic enzymes belonging to EC 1.1.1.39/40 (PHAVU_008G068700g and PHAVU_005G166400g) showed a significant increase in expression. Arabidopsis thaliana multiple mutants impaired in NAD-dependent malic enzyme activity were reported to alter the levels of several sugars, amino acids, to have low citrate and fumarate contents and to accumulate 2-oxoglutarate and succinate [47]. This supports a scenario in which $P$. vulgaris may sanction Fix ${ }^{-}$bacteroids by succinate depletion. Of note, PHAVU_010G073700g, the common bean ortholog of the $A$. thaliana high-affinity ammonium transporter AMT2 (under nitrogen regulation in the root [48]) was found 6-fold up-regulated in nifA nodules. As several endopeptidases (Supplementary Table S4) had increased transcript abundance in nifA nodules compared to wild-type (Supplementary Figure S2a and Table S5), a simple scenario in which autophagy and proteolysis contribute to the salvage of nitrogenous compounds is plausible.

We report here that the nodules infected by a nifA mutant accumulate BR relative to nodules occupied by wild-type P. phymatum. To our surprise, in contrast to the clear metabolomic profiles, the nifA nodules we sampled did not demonstrate an obvious upregulation of genes associated with BR biosynthesis. Instead, a large number (23) of the 107 P. vulgaris genes we could associate to steroids synthesis appeared repressed in nifA nodules, while only four displayed significant upregulation. It is thus possible that the increased BR content in nifA nodules originates from repressed regulation processes. For example, the putative brassinolide and castasterone glucosyl transferases UGT73C5 PHAVU_001G182400g, PHAVU_001G182300g and PHAVU_007G152800g showed downregulation, possibly preventing conjugation-driven BR deactivation and recycling. In fine, BR have been recognized to suppress early nodulation events such as infection thread formation and stimulate nodule initiation, and do interact with auxin signaling pathways [35].

We found two transcripts belonging to the auxin-responsive GRETCHEN HAGEN 3 (GH3) family (PHAVU_011G153400g and PHAVU_002G014400g) with 3 to 4-fold expression increase in nifA compared to wild-type nodules. These IAA-amido synthases potentially conjugate aspartate and other amino acids to IAA, suggesting that bacterial-derived auxins may be converted to storage forms of the hormone to regulate downstream responses. Similarly, the up-regulated PHAVU_002G038600g gene encodes a chalcone synthase homolog which, besides its pivotal role in flavonoids biosynthesis, may participate into the regulation of auxin transport. The high abundance of IAM in nifA nodules did not classically impact the expression of prominent auxin marker genes in our samples. Nevertheless, an ortholog of the A. thaliana major auxin facilitator PIN1, PHAVU_001G121100g, as well as the PIN-like auxin transporter PHAVU_010G051500g showed a decrease in relative abundance in nif $A$ compared to wild-type nodules. Likewise, an ortholog of the $A$. thaliana auxin biosynthetic gene YUC6 (PHAVU_009G105400g) was also down-regulated in the mutant nodules. A handful of less-described auxin-responsive transcripts also displayed down-regulation in our nifA dataset, but a scenario in which the accumulation of IAM triggers a profound auxin-based reprogramming of the sampled nodule is not favored. Nonetheless, it is worth to mention that two Arabidopsis BLADES-ON-PETIOLE (BOP) orthologs, PHAVU_001G124100g (AtBOP1) and PHAVU_007G248000g (AtBOP2), orthologous to the Medicago truncatula NOOT and Pisum sativum COCH root identity repressors [49], were found down-regulated in nifA nodules. Even though the determinate $P$. vulgaris nodules cease early meristematic growth, the organogenetic and tissue identity functions of these two factors resonate with the auxin and BR homeostatic changes observed in nif $A$ nodules and their aberrant clustering, which will require further attention [50].

In line with these results, a large subset of the putative proteins responsible for the maintenance of the autoregulation of nodulation (AON) were found to be significantly repressed in nifA nodules. This fabacean-specific systemic negative feedback loop normally restricts excessive nodule numbers in the plant-rhizobia interaction, presumably to balance the energy cost of hosting nitrogen-fixing bacteroids. First, the CLAVATA3/ESR (CLE)-related protein PHAVU_003G177600g (CLE12 or 13), a pre-propeptide orthologous to the Glycine max NIC1 and RIC1, together with the RIC2 ortholog PHAVU_011G135900g, 
showed significantly lower transcripts abundance in nodules occupied by the nif $A$ mutant. Nitrate-induced CLE peptides were shown to suppress soybean nodule progression via the nodulation autoregulation receptor kinase GmNARK. GmNARK is homologous to Lotus japonicus HYPERNODULATION ABERRANT ROOT FORMATION, and both proteins are homologs of the well-described A. thaliana CLAVATA1 (CLV1) [51]. The P. vulgaris CLV1 ortholog PHAVU_011G042100g was also found significantly repressed in absence of NifA. Interestingly, another CLAVATA1-related receptor kinase-like protein (PHAVU_003G231400g/AtBAM1), required for shoot apical meristem maintenance, showed reduced expression in mutant nodules, suggesting that this putative member of the CLE-CLAVATA1 signaling pathway might play as well as a role in AON. Another gene potentially involved in AON, the M. truncatula ERF/AP2 transcription factor ortholog PHAVU_010G159500g, also displayed significant lower transcripts abundance in nodules colonized by the nifA mutant. It is plausible that the nitrogen-deprived status of nif $A$ nodules represses host control over nodulation events. The nifA hypernodulating phenotype may thus arise from the deregulation of early nodule proliferation.

The most prominent functional groups of down-regulated transcripts relate to carbohydrate metabolism and plant cell wall organization and dynamics (Supplementary Figure S2b and Table S6). First, key genes associated to cellulose biosynthesis and its regulation were found repressed, including homologs of cellulose synthases or well-characterized CesA-interacting proteins (Supplementary Figures S4 and S6). Second, the plethora of plant cell wall-modifying enzymes with lower expression in nifA nodules clearly indicate a decrease in cell elongation and overall growth in this organ. The lower growth is supported by the down-regulation of several cytoskeleton-associated transcripts known to support cell wall biogenesis (core tubulin components and tubulin- or actin-binding proteins) (Supplementary Figure S4 and Table S6). Similarly, two GO terms clusters, "Regulation of developmental growth" and "Root development" were found enriched, in line with the small size of nifA-colonized nodules (Supplementary Figure S2b) [18]. Several genes belonging to the GO term "Disaccharide metabolic process", such as two trehalose 6-phosphate phosphatases, three sucrose synthases or active in sucrose catabolism (cytosolic invertase) or transport (sucrose/H+ symporter) together with a sugar isomerase, a hexose $/ \mathrm{H}+$ symporter and three nucleotide-sugar transporters showed decreased expression in nifA nodules (Supplementary Figure S4 and Table S6). This strongly suggests that carbon supply to non-fixing symbionts might be actively reduced. In contrast, we found four STP-like Major facilitator superfamily proteins significantly overexpressed in nifA Fix ${ }^{-}$nodules (Supplementary Tables S4 and S6). These sugars/H+ symporters control monosaccharides homeostasis and the over-expression of STP13 in A. thaliana improved growth and nitrogen use [52]. It is tempting to speculate that hexoses recovered from the cell wall turnover could be diverted from the inefficient nifA nodules.

The nodules colonized by the nifA mutant displayed a strong reduction in flavonoids contents compared to wild-type-colonized ones. This reduction is also reflected in the overall down-regulation of genes involved in the biosynthesis and conversion of this class of compounds. In particular, the strongly reduced transcripts abundance of three putative CYP81 family hydroxylases (Supplementary Table S4) seems to correlate with the decrease in downward isoflavonoids (Supplementary Figure S3a and Table S6). Similarly, the CYP98 family monooxygenase PHAVU_001G117900g, the caffeoyl-CoA O-methyltransferase PHAVU_003G242400g and the shikimate O-hydroxycinnamoyltransferase PHAVU_005G183200g show a coordinated reduction in expression, presumably hindering $p$-coumaroyl-CoA conversion. The same expression kinetics were found for a dozen of genes involved in phenylpropanoids biosynthesis.

Nitrogen is essential to amino and nucleic acids synthesis in plants. As expected, many repressed genes clustered in functional GO terms related to organonitrogen usage, amine, purine and amino acids metabolism under nif $A$-triggered nitrogen limitation. We could map a total of 61 P. vulgaris genes and metabolites to the KEGG pathway "Biosynthesis of amino acids" and observed a strong congruence between down-regulated metabolic genes in nifA nodules (Supplementary Figure S2b). Interestingly, P. vulgaris seems to participate 
in the net aspartate accumulation observed in nodules occupied by the nifA mutant as the asparagine synthase PHAVU_006G069300g, the asparaginase PHAVU_001G025000g or the aspartate transporter PHAVU_001G077000g showed marked reductions in expression (Supplementary Figure S3b). This further highlights the defective nitrogen assimilation by the plant host in nifA nodules. On the other hand, the glutamate synthase PHAVU_001G076400g and glutamate dehydrogenase PHAVU_004G080200g displayed lower transcription in nodules occupied by the mutant, thus the lower abundance of glutamate, glutamine and 2-oxoglutarate may directly result in the observed depletion in succinate in these tissues (Supplementary Figure S3b). The reduced expression of a functional module comprising the urate hydroxylase PHAVU_007G234300g, the hydroxyisourate hydrolase PHAVU_010G034000g, the 2-oxo-4-hydroxy-4-carboxy-5-ureidoimidazoline decarboxylase PHAVU_010G034000g and the allantoinase PHAVU_006G186700g could account for the observed decrease in allantoin levels.

Taken together, our data suggest that the bean nitrogen assimilation program is greatly affected in nifA-colonized nodules, as exemplified by the drastic down-regulation of the nitrate reductase PHAVU_009G121000g or of the nitrate-inducible, GARP-type transcriptional repressor PHAVU_003G028000g. Similarly, the A. thaliana bZIP domain transcription factor NITRATE REGULATORY GENE (NRG) ortholog PHAVU_010G050100g was repressed in absence of NifA.

\subsection{The nifA Mutant Strain Produces a Higher Amount of Auxin Compounds}

The decrease in the amount of the auxin precursor tryptophan and the increase in indole-acetamide (IAM) as well as the increase in transcript levels of Bphy_7768 coding for a IAM hydrolase (iaaH), suggested that $P$. phymatum NifA is involved in the regulation of auxin levels inside the nodule. In order to investigate a possible influence of NifA in auxins production, the amount of secreted indolics was measured in wild-type, nifA mutant and nif $A$ complemented strain grown in complex liquid medium. After growing the three strains for $16 \mathrm{~h}$, the supernatant was collected and the amount of auxins determined. Our quantification showed that the nifA mutant exported 180-fold more auxins in free-living conditions compared to the wild-type, i.e., around $26 \mu \mathrm{g} / \mathrm{mL}$. The amount of auxinic compounds produced by the mutant could be restored to wild-type levels by providing nifA on a plasmid (Figure 4). This result suggests that NifA negatively controls auxin production by the microsymbiont, not only that inhabiting root nodules as suggested by nodules metabolomes but also in free-living conditions. Using the colorimetric method, the identity of the overproduced auxin cannot be determined more precisely. However, based on our metabolomics and transcriptomics data, we speculate that the main auxinic product could be IAM and/or IAA itself. Indeed, the data suggest a statistically significant accumulation of IAM and indole-3-acetaldehyde as well as an increased transcription of Bphy_7768 (iaaH), coding for the enzyme that hydrolyzes IAM into IAA. IAA is the main auxin in plants [53] and, interestingly, the overproduction of IAA via the IAM pathway in S. meliloti strain 1021 positively affected nodulation in Medicago plants, while the IAA overproducer Rhizobium leguminosarum bv. phaseoli, did not influence nodule number in P. vulgaris [54]. In absence of alterations in the abundance of IAA-biosynthetic plant transcripts, we assume that the observed auxin accumulation originated from the peribacteroid space (PBS). Even though auxin peribacteroid membrane IAA importers have been suggested [55], no IAA exporters have been reported to date. However, the PBS in M. truncatula/S. meliloti nodules was found acidic; if low $\mathrm{pH}$ also occurs in bean PBS, the diffusion of protonated IAA through the peribacteroid membrane would be facilitated [56]. 


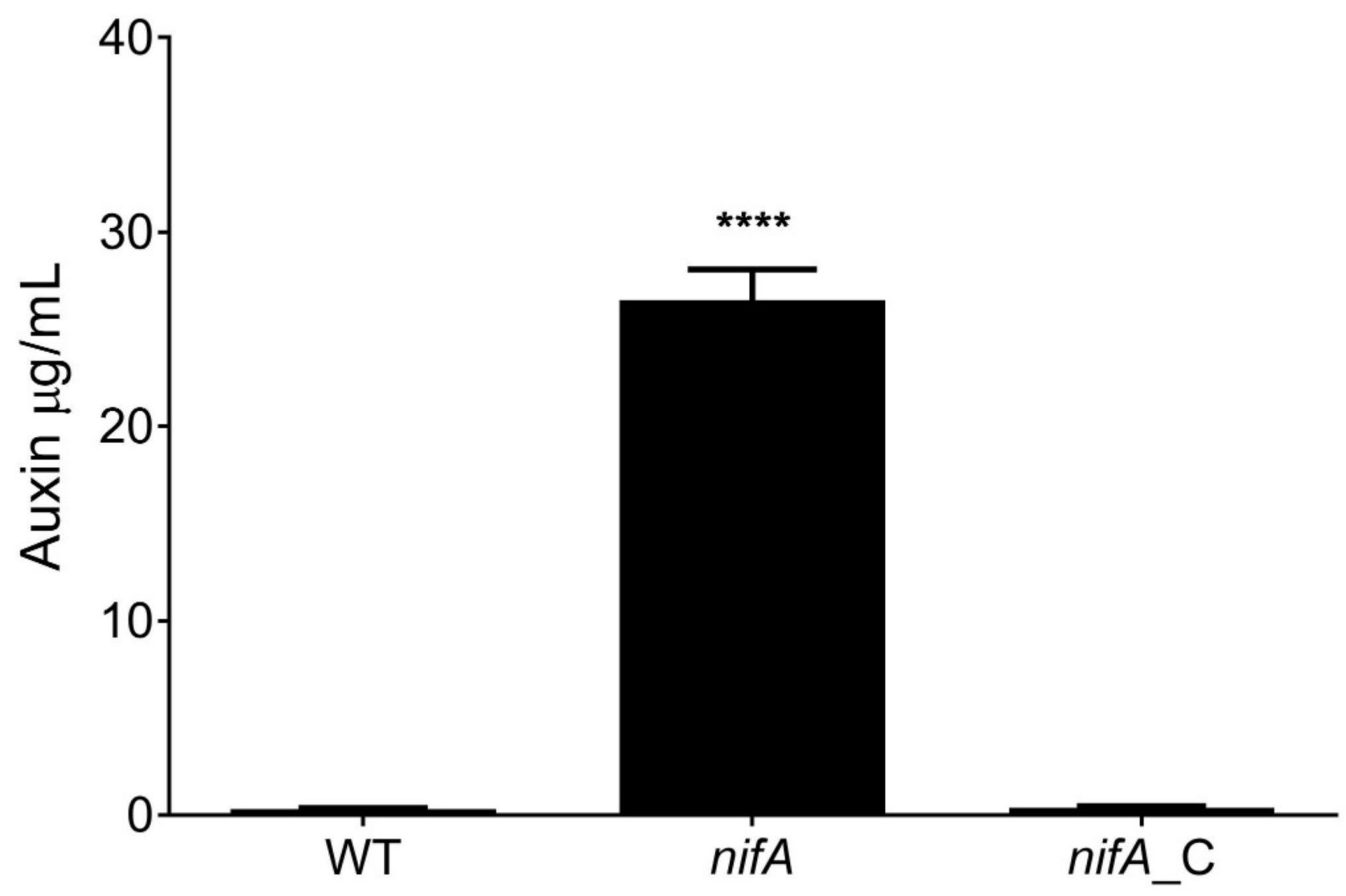

Figure 4. Auxinic compound production by P. phymatum STM815 (WT), nifA insertional mutant (nifA) and the complemented strain (nifA_C). Strains were grown in LB medium without salt for $16 \mathrm{~h}$ and the release of auxins was measured by colorimetry using indole-3-acetate (IAA) as standard. The experiment was performed with three biological replicates. Error bars indicate error of the mean (SEM). Significance was calculated by ANOVA, Tukey's test $(* * * *: p$-value $<0.0001)$.

\subsection{The nifA Mutant Strain Is Affected in Growth on Plates Containing Succinate, Malate, Glutamine and Glutamate as Only Carbon Sources}

Our metabolomics data showed a decrease in the $\mathrm{C}_{4}$-dicarboxylate succinate and in the amino acid glutamine and glutamate in nodules occupied by the nif $A$ mutant compared to wild-type nodules. Moreover, the RNA-Seq analysis showed that P. phymatum $\mathrm{C}_{4}$ dicarboxylate transporter DctA (Bphy_0225) encoding gene was down-regulated in nifA nodules (Figure 3f), although did not pass our threshold settings ( $p$-value $=0.024$ ). We therefore investigated the viability of wild-type, nifA mutant and complemented strain on several carbon sources. For this, the same number of cells $\left(10^{7}\right.$ cells) previously grown in liquid complex media, were plated in minimal media with different carbon sources. While the nifA mutant was not affected in growth in complex medium (LB without salt) and in minimal medium containing the $\mathrm{C}_{6}$ compounds glucose (ABG), the nif $A$ mutant displayed up to 100-fold reduction in cell number when grown in minimal medium with the $\mathrm{C}_{4}$ dicarboxylates succinate and malate and this defect was complemented by providing nif $A$ in trans (Figure 5). It is known that $\mathrm{C}_{4}$-dicarboxylates play a key role during symbiosis in rhizobia and that blocking the dicarboxylate transport (Dct) system leads to a nitrogen fixation failure [3]. These results suggest that NifA affect the transport of succinate and malate by regulating the Dct system in free-living conditions and during symbiosis. When we grew the cells in presence of glutamine and glutamate as only carbon sources, the growth of the nifA mutant was also found reduced one log, suggesting the involvement of NifA during the assimilation of these amino acids (Figure 5). The protonated form of ammonia, which is formed from the reduction of atmospheric nitrogen, is known to 
bind to glutamate in order to produce glutamine that is distributed and assimilated by plant cells [4].

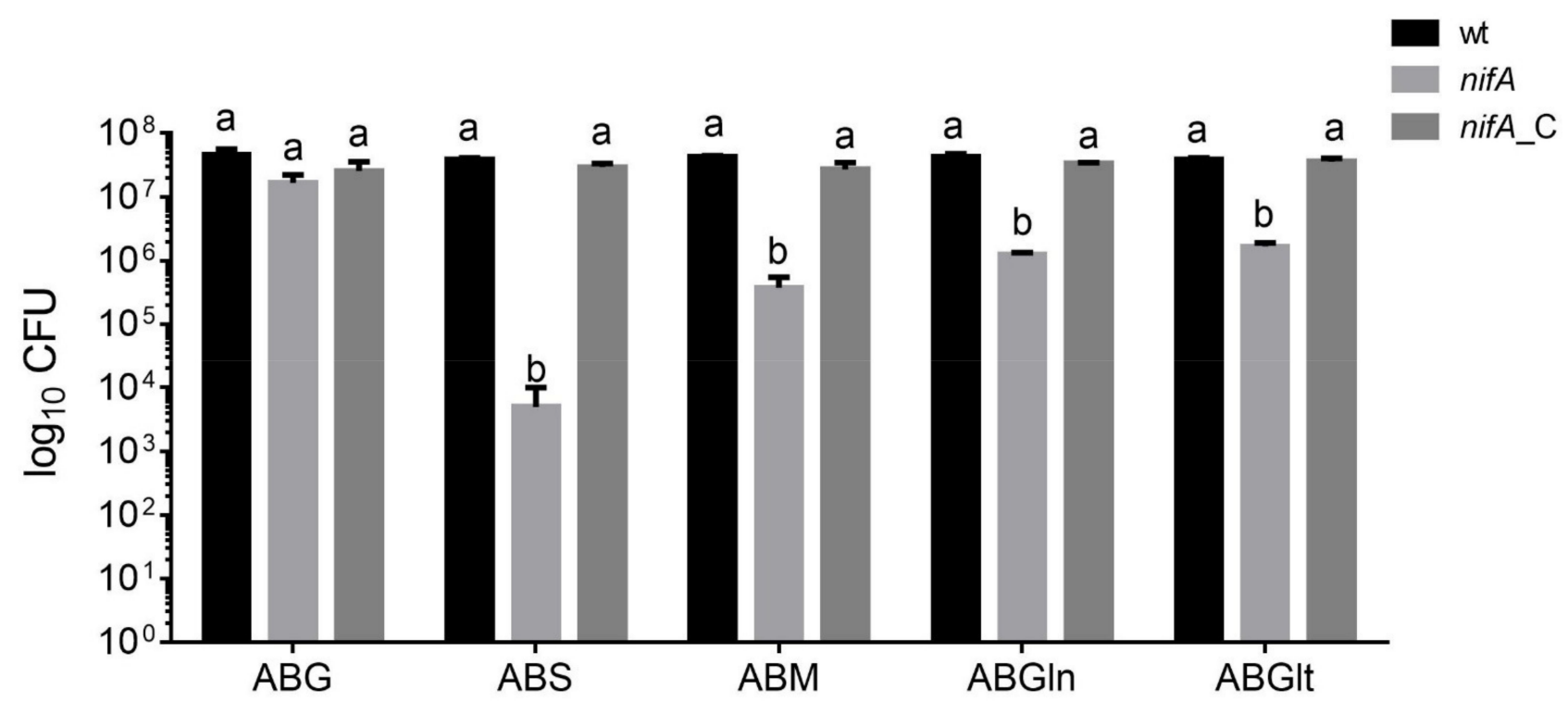

Figure 5. Growth of P. phymatum wild-type (wt), nifA mutant strain (nifA) and its complemented strain (nifA_C) in AB minimal media with different carbon sources. First, the strains were grown in full media for $16 \mathrm{~h}$, then the cells were washed and the $\mathrm{OD}_{600}$ adjusted to 0.05 . Next, serial dilutions were spotted on LB without salt rich media (LB) and $A B$ media supplemented with $10 \mathrm{mM}$ of glucose $(\mathrm{ABG})$ as a control, $\mathrm{AB}$ supplemented with $15 \mathrm{mM}$ of the $\mathrm{C}_{4}$-dicarboxylate succinate $(A B S)$ or malate $(A B M)$ and $A B$ supplemented with $12 \mathrm{mM}$ of the amino acids glutamine (ABGln) or glutamate (ABGlt). The growth of the strains is shown as $\log _{10}$ of the colony-forming units (CFU). At least three biological replicates were performed in this analysis. Error bars indicate the standard error of the mean (SEM). For each condition, values with the same letter $(a, b)$ are not significantly different, while those with different letters are (ANOVA and Tukey's test using a $p$-value $<0.05)$.

\subsection{NifA Plays a Role in Osmotic Tolerance}

Due to the observed up-regulation of several genes involved in the response to stress in nifA mutant bacteroids (the sigma factor $\mathrm{RpoH}$, a catalase, an alkyl peroxidase), we compared the sensitivity of $P$. phymatum wild-type, nif $A$ mutant and complemented strains to different kinds of stress such as acidic and alkaline $\mathrm{pH}$ ( $\mathrm{pH} 5$ and $\mathrm{pH} 8$, respectively), osmolarity ( $400 \mathrm{mM}$ of D-sorbitol), salinity $(200 \mathrm{mM}$ of $\mathrm{NaCl})$, oxidative $(35 \%, 7 \%$ and $3.5 \% \mathrm{H}_{2} \mathrm{O}_{2}$ ) and temperature (incubation at $37^{\circ} \mathrm{C}$ ). The survival of these strains was tested by spotting several dilutions on the respective plates modified according to the stress condition to be tested. After $40 \mathrm{~h}$ incubation, the three P. phymatum strains did not show any significant difference in growth under low or high $\mathrm{pH}$, salinity or temperature stress. However, the P. phymatum nifA mutant was more resistant to osmotic stress compared to the wild-type and the complemented strain (Figure 6). This phenotype could be attributed to the up-regulation of the expression of $r p o H$, coding for the sigma factor known to play a key role in the adaptation to heat-shock, osmotic and oxidative stress [44]. Nevertheless, all $P$. phymatum strains were found to be similarly sensitive to $\mathrm{H}_{2} \mathrm{O}_{2}$ (data not shown). 


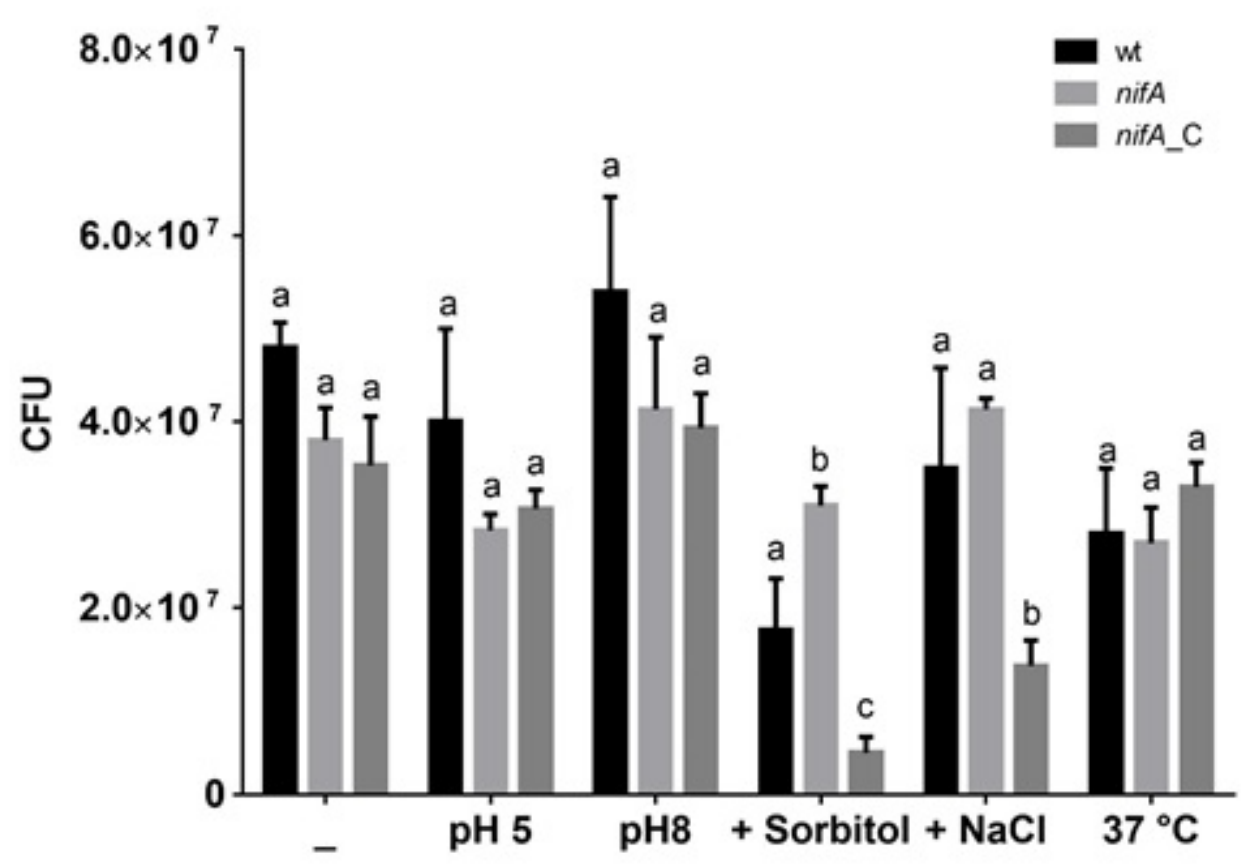

Figure 6. Sensitivity of P. phymatum wild-type (wt), nifA mutant strain (nifA) and its complemented strain (nifA_C) in LB without salt complex media subjected to different stress. Grown cultures of the three strains were adjusted to an $\mathrm{OD}_{600}$ of 0.05 , serial dilutions were spotted on the LB without salt plate (-), with pH adjusted to 5 ( $\mathrm{pH} 5$ ) or to 8 ( $\mathrm{pH} 8$ ), supplemented with $400 \mathrm{mM}$ of D-sorbitol (+Sorbitol) or with $200 \mathrm{mM}$ of $\mathrm{NaCl}(+\mathrm{NaCl})$ or on $\mathrm{LB}$ without salt plates incubated at $37^{\circ} \mathrm{C}$. The survival of the strains is shown as the colony-forming units (CFU). At least three biological replicates were performed in this analysis. Error bars indicate the standard error of the mean (SEM). For each condition, values with the same letter ( $a, b, c)$ are not significantly different, while those with different letters are (ANOVA and Tukey's test using a $p$-value $<0.05$ ).

\section{Materials and Methods}

\subsection{Bacterial Strains, Media and Cultivation}

The primers, plasmids and bacterial strains used in this work are listed in the Supplementary Materials (Supplementary Table S7). Escherichia coli strains were habitually grown under aerobic conditions at $37^{\circ} \mathrm{C}$ in Luria-Bertani liquid medium (LB) [57], while P. phymatum STM815 strains were aerobically cultured at $28{ }^{\circ} \mathrm{C}$ in a modified LB liquid medium without salt. Where necessary, the antibiotics kanamycin $(25 \mu \mathrm{g} / \mathrm{mL}$ for E. coli and $50 \mu \mathrm{g} / \mathrm{mL}$ for $P$. phymatum $)$ and/or chloramphenicol $(80 \mu \mathrm{g} / \mathrm{mL}$ for P. phymatum $)$ were used.

\subsection{Plant Growth Conditions}

The surface-sterilization of the common bean seed (Phaseolus vulgaris, cv. Negro Jamapa) was carried out by soaking in absolute ethanol for five minutes followed by another five minutes of soaking in $35 \% \mathrm{H}_{2} \mathrm{O}_{2}$. Seeds were washed several times with sterile deionized water and were placed on $0.8 \%$ agarose plates [58]. After $48 \mathrm{~h}$ of germination in the dark at $28{ }^{\circ} \mathrm{C}$, the sprouted seeds were transferred into autoclaved amber yogurt jars containing nitrogen-free Jensen medium and vermiculite (VTT-Group, Muttenz, Switzerland) [59]. The cultured bacterial cells were washed and inoculated on the germinated seeds as previously described [18]. The inoculated plants were grown for 21 days in a green-house under the conditions: $22 / 25^{\circ} \mathrm{C}$ night/day temperatures with $16 \mathrm{~h}$ light $\left(160 \mu \mathrm{mol} \mathrm{m} \mathrm{m}^{-2} \mathrm{~s}^{-1}\right)$ and a constant humidity of $60 \%$. Inoculated and non-inoculated plants were watered with sterile deionized water.

\subsection{Metabolite Extraction and Data Analysis}

Metabolite abundances were compared between $P$. vulgaris root nodules infected with P. phymatum strains (wild-type or nifA insertional mutant). The metabolites extracted from 
the mature part of the uninfected P. vulgaris roots were used as root baseline to produce Figure 2. Samples of three biological replicates (plants inoculated with three P. phymatum biological replicates) two technical replicates each, per strain (P. phymatum wild-type and nifA mutant) were analyzed. After 21 days, all root nodules present on the root system were collected and flash-frozen in liquid nitrogen. The correct identity of the strains present in the nodules was verified by plating on selective media and PCR. One plant at the time was extracted from the soil and immediately processed. For inoculated plant each nodule was taken and immediately flash frozen. Approximately $30 \mathrm{mg}$ of nodules from two plants per sample were used for the extraction of metabolites using cold methanol method as previously described [25]. The uninfected roots $(30 \mathrm{mg})$ were processed in the same way as the nodules and as has been carried out in previous studies $[19,25,26]$. Next, the hydrophilic methanol extracts were injected in an Agilent 6550 QTOF instrument (Agilent Technologies, Santa Clara, CA, USA) and analyzed by non-targeted flow injection-time-of-flight mass spectrometry, as shown before [60]. A total of 437 ions with distinct $\mathrm{m} / \mathrm{z}$ were matched to expected deprotonated molecules which were then statistically analyzed with a two-tailed, heteroscedastic $t$-test using a false discovery rate (FDR) correction according to Storey and Tibshirani [61]. Metabolites showing statistically significant increased/decreased levels were selected using the following criteria: fold change (FC) threshold of $\log _{2} \geq 0.5$ or $\leq-0.5$ and $q$-value $\leq 0.01$. All the metabolomics raw data, including ions, annotations and intensities, are listed in the Supplementary Table S8. The integrated metabolic pathway analysis was performed in MetaboAnalyst 5.0 [62] using KEGG pathways as a reference [63].

\subsection{RNA-Sequencing and Data Processing}

Samples of root nodule induced by P. phymatum wild-type or mutant strains were flash-frozen in liquid nitrogen and the extraction of plant and bacterial RNA was carried out using a modified hot acid phenol protocol [64]. Two independent biological replicates were analyzed per condition. The DNase treatment for genomic DNA (gDNA) removal and the RNA quality check were performed as reported earlier [65]. Plant ribosomal RNA (rRNA) elimination was carried out using the Ribo-zero ${ }^{\text {TM }}$ Plant-Seed/Root kit (Epicentre, Madison, DC, USA) [18]. After RNA quantification, the cDNA libraries were synthesized and purified with the Encore Complete Prokaryotic RNA-Seq DR Multiplex System (NuGEN, San Carlos, CA, USA), and quantified by capillary electrophoresis using a TapeStation (Agilent Technologies) [18]. The libraries were sequenced (single end and 125 base-pair) with a HiSeq2500 instrument (Illumina, San Diego, CA, USA) [18]. The obtained reads were trimmed to $70 \mathrm{bp}$, processed and mapped to the P. phymatum STM815 genome (NC_010622.1, NC_010623.1, NC_010625.1 and NC_010627.1) [11] or to the P. vulgaris genome (NC_023759.1, NC_023758.1, NC_023757.1, NC_023756.1, NC_023755.1, NC_023754.1, NC_023753.1, NC_023752.1, NC_023751.1, NC_023750.1, NC_023749.1) [66]. To achieve this, CLC Genomics Workbench v11.0 (QIAGEN CLC bio, Aarhus, Denmark) was employed, allowing up to two mismatches per read. The statistical analysis for the differential expression of the reads uniquely mapped to the genome was conducted with the DESeq R-package version 1.38.0 [67]. For the DESeq analysis, the top 479 and 1572 significantly regulated genes from P. phymatum and P. vulgaris, respectively (ranked by ascending $p$-value), were selected. A FC threshold of $\log _{2} \geq 1$ or $\leq-1$ was applied with a $p$-value $\leq 0.02$. Functional enrichment in gene ontology terms was carried out using the Cytoscape 3.5 plugin ClueGo v2.5.8 with default settings. The complete list of all P. phymatum and P. vulgaris genes and their $\log _{2} \mathrm{FC}$ by comparing their expression in the nif $A$ mutant induced nodules versus their expression in the wild-type nodules can be found in the Supplementary Tables S2 and S3.

\subsection{Construction of P. phymatum STM815 Complemented Strains}

P. phymatum STM815 genomic DNA was isolated using the GenElute ${ }^{\mathrm{TM}}$ Bacterial Genome DNA Kit (Sigma-Aldrich, St. Louis, MO, USA), while plasmid DNA from E. coli strains was obtained by using the QIAprep Spin Miniprep Kit (Qiagen, Hilden, Germany). To generate the complemented strain of the previously constructed nifA insertional mu- 
tant [18], the P. phymatum nifA (Bphy_7728) was amplified by PCR using the primers nifA_comp_F_HindIII and nifA_comp_R_XbaI. The $2043 \mathrm{bp}$-long product was digested with the restriction enzymes HindIII and XbaI and ligated into the pBBR1MCS-2. The constructed plasmid was then mobilized to the nif $A$ mutant strain by triparental mating. The sequence of the constructed plasmid was confirmed by sequencing at Microsynth (Balgach, St. Gallen, Switzerland).

\subsection{Auxin Production}

The production of auxinic compounds by P. phymatum STM 815 wild-type and nifA mutant strains was quantified by a modified colorimetric assay from Gravel and colleagues [68]. Precultures were grown aerobically at $28^{\circ} \mathrm{C}$ in LB without salt with the corresponding antibiotics, washed twice and inoculated into $100 \mathrm{~mL}$ flasks containing $20 \mathrm{~mL}$ of LB without salt with an initial $\mathrm{OD}_{600}$ of 0.05 . Cultures were incubated at $28^{\circ} \mathrm{C}$ with $180 \mathrm{rpm}$ shacking for $16 \mathrm{~h}$ until all the strains reached an $\mathrm{OD}_{600}$ of 4 . Two $\mathrm{mL}$ of culture was then centrifuged (5000 rpm, $5 \mathrm{~min}$ ) and one $\mathrm{mL}$ of the supernatant was mixed with two $\mathrm{mL}$ of Salkowski's reagent [69]. The mixture was incubated at room temperature in the dark for $20 \mathrm{~min}$ and the absorbance was measured at $535 \mathrm{~nm}$. To quantify extracellular auxinic compounds, a $50 \mu \mathrm{g} / \mathrm{mL}$ of indole-3-acetic acid (IAA) (Sigma-Aldrich, Buchs, St. Gallen, Switzerland) solution was diluted in LB without salt to draw the standard curve. This experiment was conducted in three biological replicates.

\subsection{Carbon Source and Stress Survival Assay}

The carbon source assimilation and the stress tests of the different P. phymatum strains were assayed on agar plates containing different media, as described below. Cell growth with different carbon sources was tested on the $\mathrm{AB}$ minimal media [70] agar plates supplemented with: $15 \mathrm{mM}$ of succinate or malate; $10 \mathrm{mM}$ of glucose; $12 \mathrm{mM}$ of glutamine or glutamate. Cell sensitivity to acidic or alkaline $\mathrm{pH}$, osmotic or salt stress were tested on LB without salt medium plates with following modifications: $\mathrm{pH}$ adjusted to either 5 or 8 , supplemented with $400 \mathrm{mM}$ of D-sorbitol or supplemented with $200 \mathrm{mM}$ of $\mathrm{NaCl}$, respectively. The bacterial precultures were grown as mentioned above (see Section 3.6). Cells were collected by centrifugation, washed twice with $10 \mathrm{mM} \mathrm{MgSO}_{4}$ and adjusted to $\mathrm{OD}_{600} 0.05$. Then, 10 -fold serial dilutions were performed. Five $\mu \mathrm{L}$ of each dilution of the strains were spotted on above mentioned plates and a standard LB without salt plate as a control. The plates were incubated at $28^{\circ} \mathrm{C}$ until the colonies were countable. The cell viability in each test was determined by the colony-forming units (CFU). Similarly, the temperature stress was assayed on standard LB without salt plates and incubated at $37^{\circ} \mathrm{C}$.

\subsection{Statistical Analysis}

The statistical analysis for all the phenotypical tests (auxin production, carbon-source utilization and stress susceptibility assay) were performed with GraphPad Prism 6.0. The significant difference in auxin production was assessed using a one-way ANOVA and Tukey's test with a $p$-value $<0.05$. To analyze the cell viability using different carbon sources and under different stress factors, the CFU of three strains were analyzed with ANOVA and Tukey's test with $p$-value $<0.05$ for each condition.

\section{Conclusions}

In this study, we integrated metabolome and dual RNA-seq transcriptome data and thereby report for the first time the changes occurring in both symbiotic partners in the absence of NifA. Apart from the classical nitrogen deprivation signs observed in nonfixing bacteroids, we show that in the absence of P. phymatum NifA the level of several metabolites involved in BR and auxin biosynthesis was highly increased. Moreover, several $P$. phymatum genes related to the stress response showed an increased expression or amount in nifA mutant bacteroids. In contrast to the increased amount of auxins observed in nifA nodules, the plant host did not demonstrate canonical systemic or local auxin responses in these tissues. We speculate that the absence of NifA during the nodule initiation or 
early development mediates the emergence of clustered nodules by unbalancing BR-auxin homeostasis. Moreover, the hypernodulation phenotypes of $P$. vulgaris plants inoculated with the nifA mutant could be explained by the down-regulation of transcripts involved in AON. Further, in the absence of NifA, despite a marked nitrogen-limitation response, $P$. vulgaris nodules did not mount an efficient immune response to the mutant bacteria. These results differ from the ones we previously obtained with soybean nodules infected by a $B$. diazoefficiens NifA mutant, where a strong defense reaction was detected in form of the production of high level of phytoalexins. Finally, this study revealed that P. phymatum NifA induces not only the changes that are in part common to alpha-rhizobial symbiosis, but also other changes that are specific for P. phymatum-P. vulgaris symbiosis. Whether these NifA-dependent changes are conserved in other beta-rhizobial symbionts still remains to be elucidated, as well as the molecular mechanisms behind this regulatory network.

Supplementary Materials: The following are available online at https:/ /www.mdpi.com/article/10 $.3390 /$ metabo11070455/s1, Figure S1: Modified pathways from (a) alanine, aspartate and glutamate metabolism (https:/ / www.genome.jp/pathway /bph00250; accessed on 26 June 2021) and (b) tryptophan metabolism (https:/ / www.genome.jp/pathway/bph00380; accessed on 26 June 2021) obtained by KEGG Mapper, metabolites less accumulated and P. phymatum genes down-regulated in the nif $A$ mutant nodules compared to wild-type nodules, are represented in blue while the metabolites more accumulated and genes up-regulated are represented in red, Figure S2: Functional group network of differentially expressed $P$. vulgaris genes in nodules occupied by the P. phymatum nifA mutant compared to wild-type nodules: (a) up-regulated in bean nodules colonized by P. phymatum nifA mutant compared to wild-type and (b) down-regulated in P. phymatum nifA mutant compared to wild-type, disc size represents "Biological process" GO terms group p-value significance corrected with the Bonferroni step down method, Figure S3: Modified pathways from (a) isoflavonoids biosynthesis (https: / / www.genome.jp / pathway / pvu00943; accessed on 26 June 2021) and (b) alanine, aspartate and glutamate metabolism (https:/ / www.genome.jp/pathway/pvu00250; accessed on 26 June 2021) obtained by KEGG Mapper, metabolites less accumulated and P. vulgaris genes down-regulated in the P. phymatum nifA mutant nodules compared to wild-type nodules, are represented in blue while the metabolites more accumulated and genes up-regulated are represented in red, Table S1: List of all the metabolites detected in P. phymatum nifA nodules compared to wild-type nodules, Table S2: List of all $P$. phymatum genes with their differential expression comparing bean nodules inoculated with nif $A$ mutant to wild-type nodules, Table S3: List of all P. vulgaris genes with their differential expression comparing nodules inoculated with $P$. phymatum nifA mutant to wild-type, Table S4: Selection of $P$. vulgaris genes differentially expressed in the transcriptome analysis and discussed in the main text, Table S5: GO pathway specific terms analysis for up-regulated P. vulgaris genes from nodules colonized by P. phymatum nifA mutant compared to wild-type, Table S6: GO pathway specific terms analysis for down-regulated $P$. vulgaris genes from nodules colonized by P. phymatum nifA mutant compared to wild-type, Table S7: Bacterial strains, plasmids and primers used in this work, Table S8: Raw metabolomics data including injections (see sheet "injections"), ions (see sheet "ions"), ions annotations (see sheet "annotation") and intensities (see sheet "intensities"). References [71,72] are cited in the supplementary materials.

Author Contributions: P.B.-S., M.L., A.B. and G.P. conceived and designed the experiments; P.B.-S., M.L., Y.L. and N.Z. performed the experiments; P.B.-S., M.L., L.E., N.Z., A.B. and G.P. analyzed the data, P.B.-S., A.B. and G.P. wrote the paper. All authors have read and agreed to the published version of the manuscript.

Funding: This research was funded by Swiss National Science Foundation, grant number 31003A_179322 to G.P.

Institutional Review Board Statement: Not applicable.

Informed Consent Statement: Not applicable.

Data Availability Statement: The RNA-sequencing raw data files obtain in this work are accessible through the GEO Series accession number GSE176287. 
Acknowledgments: We acknowledge Christian H. Ahrens for constructive feedback on the manuscript. We are thankful to the Functional Genomic Center Zurich (FGCZ) for generating the RNA-seq data and Marta Adriana Pinto-Carbó for helping in bioinformatics. We are grateful to Elina Leu for helping with the phenotypical characterization, Eulogio Bedmar (EEZ-CSIC, Granada, Spain) for providing common bean and Kari Huwiler for helping in reproducing them.

Conflicts of Interest: The authors declare no conflict of interest.

\section{References}

1. Fowler, D.; Coyle, M.; Skiba, U.; Sutton, M.A.; Cape, J.N.; Reis, S.; Sheppard, L.J.; Jenkins, A.; Grizzetti, B.; Galloway, J.N.; et al. The global nitrogen cycle in the twenty-first century. Philos. Trans. R. Soc. B Biol. Sci. 2013, 368. [CrossRef]

2. Poole, P.; Allaway, D. Carbon and nitrogen metabolism in Rhizobium. Adv. Microb. Physiol. 2000, 43, 117-163. [CrossRef] [PubMed]

3. Yurgel, S.N.; Kahn, M.L. Dicarboxylate transport by rhizobia. FEMS Microbiol. Rev. 2004, 28, 489-501. [CrossRef] [PubMed]

4. Udvardi, M.; Poole, P.S. Transport and metabolism in legume-rhizobia symbioses. Annu. Rev. Plant Biol. 2013, 64, 781-805. [CrossRef]

5. Masson-Boivin, C.; Giraud, E.; Perret, X.; Batut, J. Establishing nitrogen-fixing symbiosis with legumes: How many rhizobium recipes? Trends Microbiol. 2009, 17, 458-466. [CrossRef]

6. Bontemps, C.; Elliott, G.N.; Simon, M.F.; Dos Reis Júnior, F.B.; Gross, E.; Lawton, R.C.; Neto, N.E.; De Fátima Loureiro, M.; De Faria, S.M.; Sprent, J.I.; et al. Burkholderia species are ancient symbionts of legumes. Mol. Ecol. 2010, 19, 44-52. [CrossRef] [PubMed]

7. Moulin, L.; Munive, A.; Dreyfus, B.; Boivin-Masson, C. Nodulation of legumes by members of the beta-subclass of Proteobacteria. Nature 2001, 411, 948. [CrossRef]

8. $\quad$ Elliott, G.N.; Chen, W.M.; Chou, J.H.; Wang, H.C.; Sheu, S.Y.; Perin, L.; Reis, V.M.; Moulin, L.; Simon, M.F.; Bontemps, C.; et al. Burkholderia phymatum is a highly effective nitrogen-fixing symbiont of Mimosa spp. and fixes nitrogen ex planta. New Phytol. 2006, 173, 168-180. [CrossRef]

9. Gyaneshwar, P.; Hirsch, A.M.; Moulin, L.; Chen, W.; Elliott, G.N.; Bontemps, C.; Santos, P.E.L.; Gross, E.; Bueno, F.; Sprent, J.I.; et al. Legume-nodulating Betaproteobacteria: Diversity, Host Range, and Future Prospects. Mol. Plant Microbe Interact. 2011, 24, 1276-1288. [CrossRef] [PubMed]

10. Mishra, R.P.N.; Tisseyre, P.; Melkonian, R.; Chaintreuil, C.; Miché, L.; Klonowska, A.; Gonzalez, S.; Bena, G.; Laguerre, G.; Moulin, L. Genetic diversity of Mimosa pudica rhizobial symbionts in soils of French Guiana: Investigating the origin and diversity of Burkholderia phymatum and other beta-rhizobia. FEMS Microbiol. Ecol. 2012, 79, 487-503. [CrossRef]

11. Moulin, L.; Klonowska, A.; Caroline, B.; Booth, K.; Vriezen, J.A.C.; Melkonian, R.; James, E.K.; Young, J.P.W.; Bena, G.; Hauser, L.; et al. Complete Genome sequence of Burkholderia phymatum STM815 ${ }^{\mathrm{T}}$, a broad host range and efficient nitrogen-fixing symbiont of Mimosa species. Stand. Genomic Sci. 2014, 9, 763-774. [CrossRef]

12. Lemaire, B.; Chimphango, S.B.M.; Stirton, C.; Rafudeen, S.; Honnay, O.; Smets, E.; Chen, W. Biogeographical patterns of legume-nodulating Burkholderia spp.: From African fynbos to continental scales. Appl. Environ. Microbiol. 2016, 82, 5099-5115. [CrossRef]

13. Lee, A.; Hirsch, A.M. Signals and responses: Choreographing the complex interaction between legumes and $\alpha$ - and $\beta$-rhizobia. Plant Signal. Behav. 2006, 1, 161-168. [CrossRef] [PubMed]

14. Ledermann, R.; Schulte, C.C.M.; Poole, P.S. How rhizobia adapt to the nodule environment. J. Bacteriol. 2021, 203. [CrossRef]

15. Kuzma, M.M.; Hunt, S.; Layzell, D.B. Role of oxygen in the limitation and inhibition of nitrogenase activity and respiration rate in individual soybean nodules. Plant Physiol. 1993, 101, 161-169. [CrossRef]

16. Dixon, R.; Kahn, D. Genetic regulation of biological nitrogen fixation. Nat. Rev. Microbiol. 2004, 2, 621-631. [CrossRef]

17. Fischer, H.M. Genetic regulation of nitrogen fixation in rhizobia. Microbiol. Rev. 1994, 58, 352-386. [CrossRef]

18. Lardi, M.; Liu, Y.; Purtschert, G.; de Campos, S.B.; Pessi, G. Transcriptome analysis of Paraburkholderia phymatum under nitrogen starvation and during symbiosis with Phaseolus vulgaris. Genes 2017, 8, 389. [CrossRef]

19. Lardi, M.; Liu, Y.; Giudice, G.; Ahrens, C.H.; Zamboni, N.; Pessi, G. Metabolomics and transcriptomics identify multiple downstream targets of Paraburkholderia phymatum $\sigma^{54}$ during symbiosis with Phaseolus vulgaris. Int. J. Mol. Sci. 2018, 19, 1049. [CrossRef] [PubMed]

20. Bobik, C.; Meilhoc, E.; Batut, J. FixJ: A major regulator of the oxygen limitation response and late symbiotic functions of Sinorhizobium meliloti. J. Bacteriol. 2006, 188, 4890-4902. [CrossRef]

21. Hauser, F.; Lindemann, A.; Vuilleumier, S.; Patrignani, A.; Schlapbach, R.; Fischer, H.M.; Hennecke, H. Design and validation of a partial-genome microarray for transcriptional profiling of the Bradyrhizobium japonicum symbiotic gene region. Mol. Genet. Genomics 2006, 275, 55-67. [CrossRef] [PubMed]

22. Hauser, F.; Pessi, G.; Friberg, M.; Weber, C.; Rusca, N.; Lindemann, A.; Fischer, H.M.; Hennecke, H. Dissection of the Bradyrhizobium japonicum NifA $+\sigma^{54}$ regulon, and identification of a ferredoxin gene $(f d x N)$ for symbiotic nitrogen fixation. Mol. Genet. Genomics 2007, 278, 255-271. [CrossRef] [PubMed]

23. Salazar, E.; Javier Díaz-Mejía, J.; Moreno-Hagelsieb, G.; Martínez-Batallar, G.; Mora, Y.; Mora, J.; Encarnación, S. Characterization of the NifA-RpoN regulon in Rhizobium etli in free life and in symbiosis with Phaseolus vulgaris. Appl. Environ. Microbiol. 2010, 76, 4510-4520. [CrossRef] 
24. Sarkar, A.; Reinhold-Hurek, B. Transcriptional profiling of nitrogen fixation and the role of NifA in the diazotrophic endophyte Azoarcus sp. strain BH72. PLoS ONE 2014, 9. [CrossRef]

25. Lardi, M.; Murset, V.; Fischer, H.M.; Mesa, S.; Ahrens, C.H.; Zamboni, N.; Pessi, G. Metabolomic profiling of Bradyrhizobium diazoefficiens -induced root nodules reveals both host plant-specific and developmental signatures. Int. J. Mol. Sci. 2016, 17, 815. [CrossRef]

26. Bellés-Sancho, P.; Lardi, M.; Liu, Y.; Hug, S.; Pinto-Carbó, M.A.; Zamboni, N.; Pessi, G. Paraburkholderia phymatum homocitrate synthase NifV plays a key role for nitrogenase activity during symbiosis with papilionoids and in free-living growth conditions. Cells 2021, 10, 952. [CrossRef]

27. Barsomian, G.D.; Urzainqui, A.; Lohman, K.; Walker, G.C. Rhizobium meliloti mutants unable to synthesize anthranilate display a novel symbiotic phenotype. J. Bacteriol. 1992, 174, 4416-4426. [CrossRef]

28. Prasad, C.K.; Vineetha, K.E.; Hassani, R.; Gupta, R.; Randhawa, G.S. Isolation and symbiotic characterization of aromatic amino acid auxotrophs of Sinorhizobium meliloti. Indian J. Exp. Biol. 2000, 38, 1041-1049.

29. Flores-Tinoco, C.E.; Tschan, F.; Fuhrer, T.; Margot, C.; Sauer, U.; Christen, M.; Christen, B. Co-catabolism of arginine and succinate drives symbiotic nitrogen fixation. Mol. Syst. Biol. 2020, 16, 1-18. [CrossRef] [PubMed]

30. Koch, M.; Delmotte, N.; Ahrens, C.H.; Omasits, U.; Schneider, K.; Danza, F.; Padhi, B.; Murset, V.; Braissant, O.; Vorholt, J.A.; et al. A link between arabinose utilization and oxalotrophy in Bradyrhizobium japonicum. Appl. Environ. Microbiol. 2014, 80, $2094-2101$. [CrossRef] [PubMed]

31. Shaw, L.J.; Morris, P.; Hooker, J.E. Perception and modification of plant flavonoid signals by rhizosphere microorganisms. Environ. Microbiol. 2006, 8, 1867-1880. [CrossRef] [PubMed]

32. Kumar, S.; Pandey, A.K. Chemistry and biological activities of flavonoids: An overview. Sci. World J. 2013, 2013. [CrossRef] [PubMed]

33. Peer, W.A.; Murphy, A.S. Flavonoids and auxin transport: Modulators or regulators? Trends Plant Sci. 2007, 12, 556-563. [CrossRef]

34. Fridman, Y.; Savaldi-Goldstein, S. Brassinosteroids in growth control: How, when and where. Plant Sci. 2013, 209, 24-31. [CrossRef] [PubMed]

35. McGuiness, P.N.; Reid, J.B.; Foo, E. Brassinosteroids play multiple roles in nodulation of pea via interactions with ethylene and auxin. Planta 2020, 252, 1-8. [CrossRef]

36. Nolan, T.M.; Vukasinović, N.; Liu, D.; Russinova, E.; Yin, Y. Brassinosteroids: Multidimensional regulators of plant growth, development, and stress responses. Plant Cell 2020, 32, 298-318. [CrossRef] [PubMed]

37. Nadzieja, M.; Kelly, S.; Stougaard, J.; Reid, D. Epidermal auxin biosynthesis facilitates rhizobial infection in Lotus japonicus. Plant J. 2018, 95, 101-111. [CrossRef]

38. Ferguson, B.J.; Ross, J.J.; Reid, J.B. Nodulation phenotypes of gibberellin and brassinosteroid mutants of pea. Plant Physiol. 2005, 138, 2396-2405. [CrossRef]

39. Foo, E.; Ferguson, B.J.; Reid, J.B. The potential roles of strigolactones and brassinosteroids in the autoregulation of nodulation pathway. Ann. Bot. 2014, 113, 1037-1045. [CrossRef]

40. Verbon, E.H.; Trapet, P.L.; Stringlis, I.A.; Kruijs, S.; Bakker, P.A.H.M.; Pieterse, C.M.J. Iron and Immunity. Annu. Rev. Phytopathol. 2017, 55, 355-375. [CrossRef]

41. Yura, T.; Nakahigashi, K. Regulation of the heat-shock response. Curr. Opin. Microbiol. 1999, 2, 153-158. [CrossRef]

42. Mitsui, H.; Sato, T.; Sato, Y.; Ito, N.; Minamisawa, K. Sinorhizobium meliloti $\mathrm{RpoH}_{1}$ is required for effective nitrogen-fixing symbiosis with alfalfa. Mol. Genet. Genomics 2004, 271, 416-425. [CrossRef]

43. Delory, M.; Hallez, R.; Letesson, J.J.; De Bolle, X. An RpoH-like heat shock sigma factor is involved in stress response and virulence in Brucella melitensis 16M. J. Bacteriol. 2006, 188, 7707-7710. [CrossRef] [PubMed]

44. Martínez-Salazar, J.M.; Sandoval-Calderón, M.; Guo, X.; Castillo-Ramírez, S.; Reyes, A.; Loza, M.G.; Rivera, J.; AlvaradoAffantranger, X.; Sánchez, F.; González, V.; et al. The Rhizobium etli RpoH1 and RpoH2 sigma factors are involved in different stress responses. Microbiology 2009, 155, 386-397. [CrossRef] [PubMed]

45. Brahmachary, P.; Wang, G.; Benoit, S.L.; Weinberg, M.V.; Maier, R.J.; Hoover, T.R. The human gastric pathogen Helicobacter pylori has a potential acetone carboxylase that enhances its ability to colonize mice. BMC Microbiol. 2008, 8, 1-8. [CrossRef]

46. Tellis, M.; Mathur, M.; Gurjar, G.; Kadoo, N.; Gupta, V. Identification and functionality prediction of pathogenesis-related protein 1 from legume family. Proteins Struct. Funct. Bioinforma. 2017, 85, 2066-2080. [CrossRef]

47. Tronconi, M.A.; Fahnenstich, H.; Gerrard Weehler, M.C.; Andreo, C.S.; Flügge, U.I.; Drincovich, M.F.; Maurino, V.G. Arabidopsis NAD-malic enzyme functions as a homodimer and heterodimer and has a major impact on nocturnal metabolism. Plant Physiol. 2008, 146, 1540-1552. [CrossRef]

48. Peng, M.; Bi, Y.M.; Zhu, T.; Rothstein, S.J. Genome-wide analysis of Arabidopsis responsive transcriptome to nitrogen limitation and its regulation by the ubiquitin ligase gene NLA. Plant Mol. Biol. 2007, 65, 775-797. [CrossRef]

49. Couzigou, J.M.; Mondy, S.; Sahl, L.; Gourion, B.; Ratet, P. To be or noot to be: Evolutionary tinkering for symbiotic organ identity. Plant Signal. Behav. 2013, 8, 3-6. [CrossRef]

50. Shimada, S.; Komatsu, T.; Yamagami, A.; Nakazawa, M.; Matsui, M.; Kawaide, H.; Natsume, M.; Osada, H.; Asami, T.; Nakanoa, T. Formation and dissociation of the BSS1 protein complex regulates plant development via brassinosteroid signaling. Plant Cell 2015, 27, 375-390. [CrossRef] [PubMed] 
51. Reid, D.E.; Ferguson, B.J.; Hayashi, S.; Lin, Y.H.; Gresshoff, P.M. Molecular mechanisms controlling legume autoregulation of nodulation. Ann. Bot. 2011, 108, 789-795. [CrossRef]

52. Schofield, R.A.; Bi, Y.M.; Kant, S.; Rothstein, S.J. Over-expression of STP13, a hexose transporter, improves plant growth and nitrogen use in Arabidopsis thaliana seedlings. Plant Cell Environ. 2009, 32, 271-285. [CrossRef] [PubMed]

53. Zhao, Y. Auxin biosynthesis and its role in plant development. Annu. Rev. Plant Biol. 2010, 61, 49-64. [CrossRef] [PubMed]

54. Pii, Y.; Crimi, M.; Cremonese, G.; Spena, A.; Pandolfini, T. Auxin and nitric oxide control indeterminate nodule formation. BMC Plant Biol. 2007, 7, 1-11. [CrossRef] [PubMed]

55. Rosendahl, L.; Jochimsen, B.U. In vitro indole-3-acetic acid uptake in symbiosomes from soybean (Glycine max L.) root nodules. Symbiosis 1995, 19, 99-110.

56. Pierre, O.; Engler, G.; Hopkins, J.; Brau, F.; Boncompagni, E.; Hérouart, D. Peribacteroid space acidification: A marker of mature bacteroid functioning in Medicago truncatula nodules. Plant Cell Environ. 2013, 36, 2059-2070. [CrossRef] [PubMed]

57. Miller, J.H. Experiments in Molecular Genetics. In The Quarterly Review of Biology; Cold Spring Harbor Lab Press: Cold Spring Harbor, NY, USA, 1972; pp. 352-355. ISBN 0879691069.

58. Talbi, C.; Delgado, M.J.; Girard, L.; Ramírez-Trujillo, A.; Caballero-Mellado, J.; Bedmar, E.J. Burkholderia phymatum strains capable of nodulating Phaseolus vulgaris are present in moroccan soils. Appl. Environ. Microbiol. 2010, 76, 4587-4591. [CrossRef]

59. Vincent, J.M. A Manual for the Practical Study of the Root-Nodule Bacteria; IBP Handbk 15 Oxford and Edinburgh; Blackwell Scientific Publications: Hoboken, NJ, USA, 1970; ISBN 0632064102.

60. Fuhrer, T.; Heer, D.; Begemann, B.; Zamboni, N. High-throughput, accurate mass metabolome profiling of cellular extracts by flow injection-time-of-flight mass spectrometry. Anal. Chem. 2011, 83, 7074-7080. [CrossRef]

61. Storey, J.D.; Tibshirani, R. Statistical significance for genomewide studies. Proc. Natl. Acad. Sci. USA 2003, 100, 9440-9445. [CrossRef]

62. Pang, Z.; Chong, J.; Zhou, G.; de Lima Morais, D.A.; Chang, L.; Barrette, M.; Gauthier, C.; Jacques, P.-É.; Li, S.; Xia, J. MetaboAnalyst 5.0: Narrowing the gap between raw spectra and functional insights. Nucleic Acids Res. 2021, 49, 388-396. [CrossRef]

63. Kanehisa, M.; Sato, Y. KEGG Mapper for inferring cellular functions from protein sequences. Protein Sci. 2020, 29 , 28-35. [CrossRef]

64. Pessi, G.; Ahrens, C.H.; Rehrauer, H.; Lindemann, A.; Hauser, F.; Fischer, H.M.; Hennecke, H. Genome-wide transcript analysis of Bradyrhizobium japonicum bacteroids in soybean root nodules. Mol. Plant-Microbe Interact. 2007, 20, 1353-1363. [CrossRef]

65. Lardi, M.; Aguilar, C.; Pedrioli, A.; Omasits, U.; Suppiger, A.; Cárcamo-Oyarce, G.; Schmid, N.; Ahrens, C.H.; Eberl, L.; Pessi, G. $\sigma^{54}$-dependent response to nitrogen limitation and virulence in Burkholderia cenocepacia strain H111. Appl. Environ. Microbiol. 2015, 81, 4077-4089. [CrossRef]

66. Schmutz, J.; McClean, P.E.; Mamidi, S.; Wu, G.A.; Cannon, S.B.; Grimwood, J.; Jenkins, J.; Shu, S.; Song, Q.; Chavarro, C.; et al. A reference genome for common bean and genome-wide analysis of dual domestications. Nat. Genet. 2014, 46, 707-713. [CrossRef]

67. Anders, S.; Huber, W. Differential expression and sequence analysis for sequence count data. Genome Biol. 2010, 11, R106. [CrossRef] [PubMed]

68. Gravel, V.; Antoun, H.; Tweddell, R.J. Growth stimulation and fruit yield improvement of greenhouse tomato plants by inoculation with Pseudomonas putida or Trichoderma atroviride: Possible role of indole acetic acid (IAA). Soil Biol. Biochem. 2007, 39, 1968-1977. [CrossRef]

69. Gordon, S.A.; Weber, R.P. Colorimetric estimation of indole-3-acetic acid. Plant Physiol. 1951, 26, 192-195. [CrossRef]

70. Liu, Y.; Bellich, B.; Hug, S.; Eberl, L.; Cescutti, P.; Pessi, G. The exopolysaccharide cepacian plays a role in the establishment of the Paraburkholderia phymatum - Phaseolus vulgaris symbiosis. Front. Microbiol. 2020, 11, 1-13. [CrossRef]

71. Elzer, P.H.; Roop, R.M.; Kovach, M.E.; Robertson, G.T.; Peterson, K.M.; Steven Hill, D.; Farris, M.A. Four new derivatives of the broad-host-range cloning vector pBBR1MCS, carrying different antibiotic-resistance cassettes. Gene 1995, 166, 175-176. [CrossRef]

72. Phadnis, S.H.; Berg, D.E. Identification of base pairs in the outside end of insertion sequence IS50 that are needed for IS50 and Tn5 transposition. Proc. Natl. Acad. Sci. USA 1987, 84, 9118-9122. [CrossRef] [PubMed] 